Brazilian Journal

of Chemical

ISSN 0104-6632

Engineering

Printed in Brazil

www.scielo.br/bjce

Vol. 34, No. 03, pp. 759 - 773, July - September, 2017

$($ (c) $)$ EY

dx.doi.org/10.1590/0104-6632.20170343s20150584

\title{
ANSBBR APPLIED TO BIOMETHANE PRODUCTION FOR VINASSE TREATMENT: EFFECTS OF ORGANIC LOADING, FEED STRATEGY AND TEMPERATURE
}

\author{
W.A. Almeida ${ }^{1}$, S.M. Ratusznei ${ }^{2}$, M. Zaiat ${ }^{1}$ and J.A.D. Rodrigues ${ }^{2, *}$ \\ ${ }^{1}$ Escola de Engenharia de São Carlos, Universidade de São Paulo (USP), Av. Trabalhador São-Carlense 400, \\ 13566-590, São Carlos-SP, Brasil. \\ ${ }^{2}$ Escola de Engenharia Mauá, Instituto Mauá de Tecnologia (IMT), Praça Mauá 1, \\ 09580-900, São Caetano do Sul-SP, Brasil. \\ *E-mail: rodrigues@maua.br
}

(Submitted: September 14, 2015; Revised: April 19, 2016; Accepted: June 3, 2016)

\begin{abstract}
This study assessed the feasibility of an anaerobic sequencing batch and fed-batch biofilm reactor (AnSBBR) with mechanical stirring for vinasse treatment and biomethane production. The amount of liquid medium used was $3 \mathrm{~L}$, and the treated volume was $1 \mathrm{~L}$ per cycle. The cycle time was $8 \mathrm{~h}$, with feeding times of $10 \mathrm{~min}$ (batch mode) and $240 \mathrm{~min}$ (fed-batch mode). Methane productivity increased with the increase in organic load from 1.0 to $10.0 \mathrm{gCOD}$. $\mathrm{L}^{-}$ ${ }^{1} \cdot \mathrm{d}^{-1}$. The maximum molar productivity and yield of methane were $123.4 \mathrm{molCH} \cdot \mathrm{m}^{-3} \cdot \mathrm{d}^{-1}$ and $13.8 \mathrm{mmolCH}_{4} \cdot \mathrm{gCOD}^{-1}$ ( $88 \%$ of the theoretical), respectively. These parameters were lower in fed-batch mode than in batch mode and were lower at $45^{\circ} \mathrm{C}$ than at $30^{\circ} \mathrm{C}$ due to biomass adaptation. In general, the values of the kinetic parameters increased with organic load and were similar for the batch and fed-batch modes. Therefore, the increase in organic load positively influenced the process by increased COD removal and lower volatile acids accumulation as the load increased. The batch mode performed better than did the fed-batch mode and $30^{\circ} \mathrm{C}$ was more suitable than $45^{\circ} \mathrm{C}$ to produce methane under the studied conditions.
\end{abstract}

Keywords: AnSBBR; biomethane; applied organic load; feed strategy; temperature.

\section{INTRODUCTION}

Vinasse disposal in soil is widely used because vinasse is rich in many nutrients and minerals that are essential to plant growth. However, fertirrigation with vinasse may change physical and chemical characteristics of the soil. This activity leads to the soil salinisation, mainly due to the high concentration of potassium in vinasse. These issues show that there is a need to develop more suitable use options for this type of ethanol production effluent (Santos et al., 2013). Biological treatment is recognized as

\footnotetext{
* To whom correspondence should be addressed
}

an effective method of treatment for the highly polluted wastewaters that result from agroindustry, including distilleries. Anaerobic treatment can be used to convert a significant portion of the organic matter into biogas, which can be used as an energy source in the distillery (Pant and Adholeya, 2007; Vlissidis and Zouboulis, 1993; Wilkie et al., 2000; Cesaro and Belgiorno, 2015).

Within this framework, the anaerobic sequencing batch reactors, ASBR (free cells) and AnSBBR (immobilized cells), are being largely studied for bioenergy generation and environmental compliance (Zaiat et al., 2001). Arooj et al. (2008) and Kim et al. (2005) used an ASBR for 
hydrogen production and they analysed the effects of the hydraulic retention time on the process and the effects of the substrate concentration, respectively.

Other researchers used an ASBR for methane production: Massé et al. (2004), studying the effect of scale up; Cassidy et al. (2008a; 2008b), assessing the influence of the organic load rate, solid retention time, and food/microorganism rate; Selma et al. (2010), analysing the effects of organic load (by increasing influent concentration) and the feed strategy (batch or fed-batch); and Silva et al. (2013), varying the organic load, the reactor feed time and the cycle length. On the other hand, Ndegwa et al. (2005), aiming at reactor optimization, and Ruíz et al. (2002), investigating the kinetics of the degradation process, used ASBR for biogas production.

Finally, some papers related to AnSBBR and methane production regarding feed strategy and organic load improvement: Lovato et al. (2012) studied the effects of feed strategy treating the effluent from biodiesel production; Bezerra et al. (2011) treated the same effluent to test the effect of the organic load; and Lullio et al. (2014) aimed at integrating hydrogen and methane production treating the effluent of hydrogen production to produce methane. Only a few studies involved the use of an AnSBBR to produce methane, and there are no papers in the published literature regarding the use of vinasse as a substrate. In addition, note that the anaerobic process is assuming importance in bioenergy production (hydrogen and methane) via the biogas resulting from the biotransformation of polluting substances.

In view of the aspects presented, this study analysed the performance of an anaerobic sequencing batch and fedbatch biofilm reactor (AnSBBR) with mechanical stirring for vinasse treatment and biomethane production. The influence of the applied volumetric organic load (AVOL - from 1.0 to $10.0 \mathrm{gCOD} \cdot \mathrm{L}^{-1} \cdot \mathrm{d}^{-1}$ ), feed strategy (feeding time of $10 \mathrm{~min}$ in batch mode and $240 \mathrm{~min}$ in fed-batch mode) and temperature $\left(30^{\circ} \mathrm{C}\right.$ and $\left.45^{\circ} \mathrm{C}\right)$ on the yield of methane from the consumed organic load, methane productivity, kinetic parameters and the overall factors of the degradation process were assessed.

\section{MATERIALS AND METHODS}

\section{AnSBBR with immobilised biomass and mechanical stirring}

Figure 1 presents the scheme of the bioreactor with mechanical stirring (New Brunswick Scientific model Bioflo $110^{\circledR}$ ), which was composed of a glass vessel of 20 $\mathrm{cm}$ in diameter and $30 \mathrm{~cm}$ in height, with a total volume of $7.5 \mathrm{~L}$ and a useful capacity of $6.0 \mathrm{~L}$. The support material was confined in a pierced stainless steel-316 container of $18 \mathrm{~cm}$ in height and $7.0 \mathrm{~cm}$ and $17.5 \mathrm{~cm}$ of internal and external diameter, respectively. Fixed stirring at $300 \mathrm{rpm}$ was implemented via a motor connected to the turbine type impellers of $6 \mathrm{~cm}$ in diameter, composed of two sets of six plane blades (Rushton pattern) installed at 8 and $16 \mathrm{~cm}$ from the bottom of the vessel (Michelan et al., 2009).

Feeding and discharge were performed using diaphragm pumps (Prominent models $\beta$ and Concept, respectively). An automation system composed of temporizers was responsible for starting/stopping the pumps and for stirring to implement the steps of sequencing batch operation: feeding, reaction and discharge. The temperature was controlled by water circulation into the double external wall of the reactor (Marconi model MA-184).

\section{Inoculum and inert support}

The inoculum was obtained from an UASB that treated wastewater of a slaughterhouse of poultry. The inoculum presented values of total solid concentration (TS) and total volatile solids (TVS) of 62 and 51 g.L. $\mathrm{L}^{-1}$, respectively. The material used as support was polyurethane foam (cubes of $1.0 \mathrm{~cm}$ ), with an apparent density of $23 \mathrm{~kg} \cdot \mathrm{m}^{-3}$ and a porosity of approximately $95 \%$. The anaerobic sludge was immobilized according to Zaiat et al. (1994). The support was confined inside the reactor (pierced stainless steel-316 container with $7 \mathrm{~cm}$ from the center) so that the impeller could freely rotate (Figure 1).

\section{Wastewater}

The wastewater/substrate was based on the vinasse that results from the industrial process of bioethanol production from a sugar/alcohol plant located in São Paulo, Brazil, which is produced during the purification of ethanol by distillation from the medium fermented in the previous stage. The composition of the industrial vinasse used is presented in Table 1.

According to the experimental condition, the industrial vinasse was diluted in tap water and supplemented with urea $\left(\mathrm{CH}_{4} \mathrm{~N}_{2} \mathrm{O}-5.8 \mathrm{mg} \cdot \mathrm{L}^{-1}\right.$ for each $\left.1000 \mathrm{mgCOD} \cdot \mathrm{L}^{-1}\right)$ and sodium bicarbonate $\left(\mathrm{NaHCO}_{3}-500 \mathrm{mg} . \mathrm{L}^{-1}\right.$ for each 1000 $\left.\operatorname{mgCOD} \cdot \mathrm{L}^{-1}\right)$

\section{Physical-chemical analyses and microbiological tests}

The following parameters were monitored in both the influent and the effluent: organic matter concentration non-filtered $\left(\mathrm{C}_{\mathrm{ST}}\right)$ and filtered $\left(\mathrm{C}_{\mathrm{SF}}\right)$ (as chemical oxygen demand), bicarbonate alkalinity (BA), total volatile acids (TVA), total solids (TS), total volatile solids (TVS), total suspended solids (TSS) and volatile suspended solids (VSS), as well as the $\mathrm{pH}$ (Standard Methods for the Examination of Water and Wastewater, 1995).

The analysis of biogas composition was performed by gas chromatography using an Agilent ${ }^{\circledR}$ model 7890 chromatograph that was equipped with a thermal 


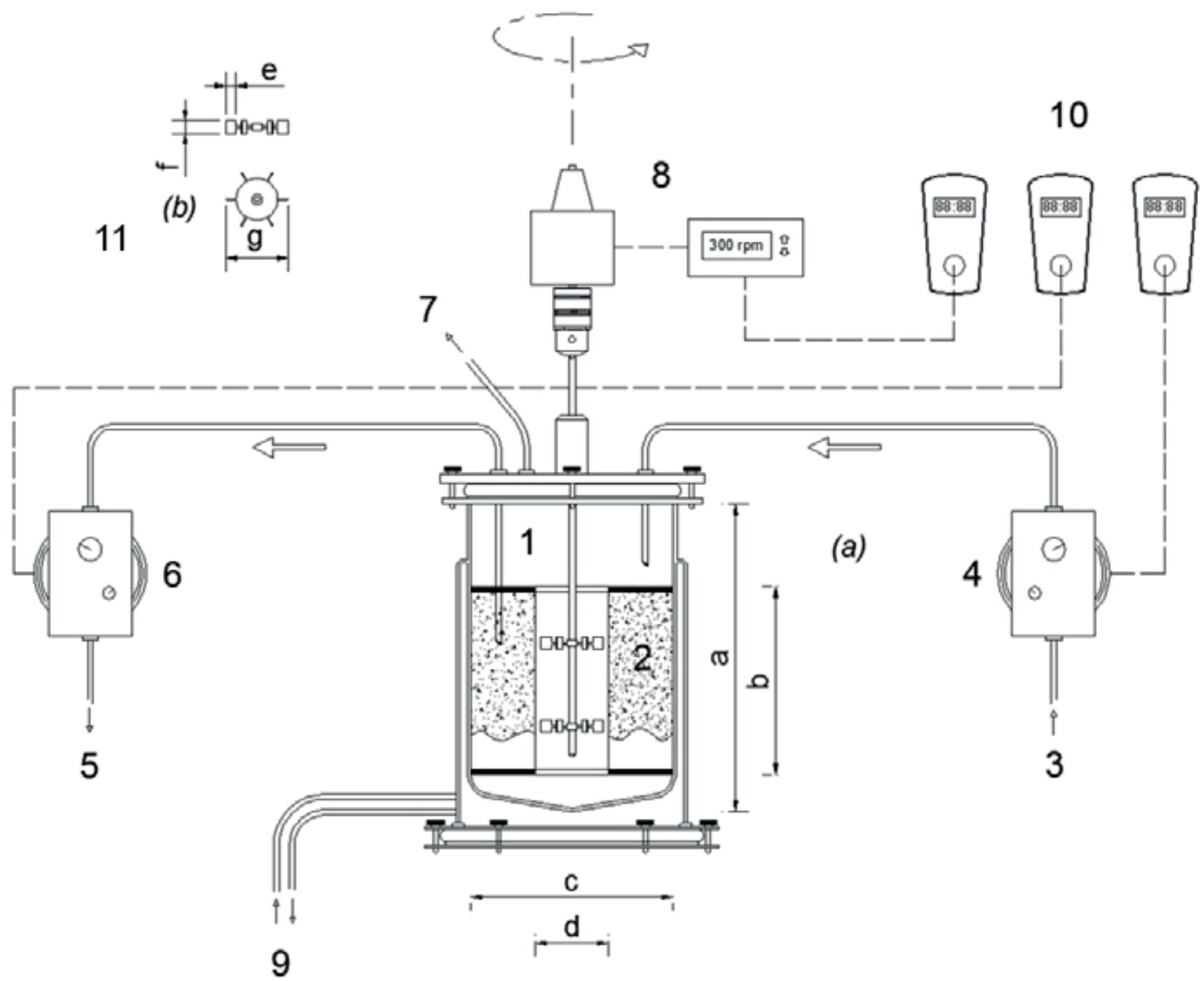

Figure 1. Scheme of the AnSBBR: (1) Bioreactor ( $a=29,5 \mathrm{~cm} ; \mathrm{b}=18 \mathrm{~cm} ; \mathrm{c}=18 \mathrm{~cm})$; (2) Stainless steel box $(\mathrm{b}=18 \mathrm{~cm}$; $d=7 \mathrm{~cm}) ;(3)$ Influent; (4) Feed pump; (5) Effluent; (6) Discharge pump; (7) Biogas outlet; (8) Stirring; (9) Thermostatic bath; (10) Automation system; (11) Turbine type propellers with six plane blades $(\mathrm{e}=2 \mathrm{~cm} ; \mathrm{f}=1.5 \mathrm{~cm} ; \mathrm{g}=6 \mathrm{~cm})$.

Table 1. Composition of the industrial vinasse.

\begin{tabular}{cc}
\hline Parameter & Concentration $\left(\mathrm{mg} . \mathrm{L}^{-1}\right) *$ \\
\hline COD & 31258 \\
$\mathrm{pH}$ & 5.6 \\
BA & 27 \\
TVA & 7633 \\
TVS & 19573 \\
TSS & 1524 \\
VSS & 1182 \\
FSS & 341 \\
VDS & 18391 \\
EtOH & 248 \\
HAc & 1339 \\
HPr & 91 \\
HBu & $0 * *$ \\
HVa & $0 * *$ \\
HCa & $0 * *$ \\
\hline
\end{tabular}

* Standard deviation $=15 \%$ (5 samples). $* *<$ Limit of detection estimated as $3 \mathrm{mg} . \mathrm{L}^{-1}$. 
conductivity detector and GS-Carbonplot column with $30 \mathrm{~m} \times 0.53 \mathrm{~mm} \times 3.0 \mu \mathrm{m}$ of film thickness. The carried gas was argon, with a flow of $3.67 \mathrm{~mL} \cdot \mathrm{min}^{-1}$, an injector temperature of $185^{\circ} \mathrm{C}$, a split ratio of 10 and an injection volume of $200 \mu \mathrm{L}$. The temperature of the oven was programmed as $40^{\circ} \mathrm{C}$ isothermal in $5 \mathrm{~min}$. The temperature of the detector was $150^{\circ} \mathrm{C}$, with a flow make up of argon of $8.33 \mathrm{~mL} \cdot \mathrm{min}^{-1}$. The total biogas production during a cycle $\left(\mathrm{V}_{\mathrm{G}}\right)$ was measured using the Ritter gas measurer model MilligasCounter.

The analysis of anaerobic metabolism (acetone, methanol, ethanol, n-butanol, acids acetic, propionic, butyric, isobutyric, valeric, isovaleric and caproic) was performed via gas chromatography (method of head-space) with external standard (isobutanol and crotonic acid) using an Agilent ${ }^{\circledR}$ model 7890 chromatograph equipped with a flame ionization detector and a HP-Innowax column with dimensions of $30 \mathrm{~m} \times 0.25 \mathrm{~mm} \times 0.25 \mu \mathrm{m}$ of film thickness. The carried gas was hydrogen, with a flow of $1.56 \mathrm{~mL} \cdot \mathrm{min}^{-1}$, an injector temperature of $250^{\circ} \mathrm{C}$, a split ratio of 10 (head-space) and an injection volume of 400 $\mu \mathrm{L}$, using an automatic injector. The temperature of the oven was programmed as follows: from $35^{\circ} \mathrm{C}$ to $38^{\circ} \mathrm{C}$ at $2^{\circ} \mathrm{C} \cdot \mathrm{min}^{-1}$, from $38^{\circ} \mathrm{C}$ to $75^{\circ} \mathrm{C}$ at $10^{\circ} \mathrm{C} \cdot \mathrm{min}^{-1}$, from $75^{\circ} \mathrm{C}$ to $120^{\circ} \mathrm{C}$ at $35^{\circ} \mathrm{C} \cdot \mathrm{min}^{-1}$, at $120^{\circ} \mathrm{C}$ for $1 \mathrm{~min}$, from $120^{\circ} \mathrm{C}$ to $170^{\circ} \mathrm{C}$ at $10^{\circ} \mathrm{C} \cdot \mathrm{min}^{-1}$ and at $170^{\circ} \mathrm{C}$ for $2 \mathrm{~min}$ (head-space). The temperature of the detector was $280^{\circ} \mathrm{C}$ (head-space), with a hydrogen flux of $30 \mathrm{~mL} \cdot \mathrm{min}^{-1}$, a synthetic air flow of $300 \mathrm{~mL} \cdot \mathrm{min}^{-1}$ and a flow make up of nitrogen of 30 $\mathrm{mL} \cdot \mathrm{min}^{-1}$.

Samples from the reactor were collected for microbiological examination. The samples were examined on glass slides using an Olympus model BX41® optical microscope with Optronics digital camera system and the Image-Pro Plus ${ }^{\circledR}$ Version 4.5.0 image acquisition software.

\section{Experimental procedure}

The experimental conditions were produced using different volumetric organic loads that were modified by the influent concentration, which ranged from $1000 \mathrm{mgCOD} . \mathrm{L}^{-1}$ to $10000 \mathrm{mgCOD} . \mathrm{L}^{-1}$. Experiments were performed in batch mode at $30^{\circ} \mathrm{C}$ that used vinasse as the influent (Conditions $\mathrm{C} 01$ to $\mathrm{C} 08$ - from $1000 \mathrm{mgCOD}^{-\mathrm{L}^{-1}}$ to $\left.10000 \mathrm{mgCOD} . \mathrm{L}^{-1}\right)$. In sequence, the feeding strategy was changed from batch to fed-batch mode while maintaining the influent concentration of vinasse at $10000 \mathrm{mgCOD} . \mathrm{L}^{-1}$ and the temperature at $30^{\circ} \mathrm{C}$ (Condition C09). The last condition was performed in batch mode with an influent concentration of $10000 \mathrm{mgCOD} . \mathrm{L}^{-1}$, with the temperature increased from $30^{\circ} \mathrm{C}$ (from the other conditions) to $45^{\circ} \mathrm{C}$, while maintaining the operation in batch mode (Condition C10). In all experimental conditions, the cycle time length was 8 hours, and the stirring was $300 \mathrm{rpm}$ (Bezerra et al., 2011; Lovato et al., 2012; Selma et al., 2010; Silva et al., 2013).
The reactor operation proceeded as follows: (a) feed of $1.0 \mathrm{~L}$ of wastewater in $10 \mathrm{~min}$ (batch mode) or $240 \mathrm{~min}$ (fed-batch mode); (b) agitation and reaction (for fed-batch mode, the feeding time is included); and (c) discharge of $1.0 \mathrm{~L}$ in $10 \mathrm{~min}$. A cycle was completed while maintaining a residual volume of $2.0 \mathrm{~L}$ from the total volume of liquid medium in the reactor of $3.0 \mathrm{~L}$. In sequence, a new cycle started.

Once stable experimental conditions were achieved, profiles along the cycle for some of the monitored parameters were made. The parameters of interest were filtered organic matter concentration, bicarbonate alkalinity, total volatile acids, intermediate metabolites, biogas (volume and composition) and $\mathrm{pH}$. The total volume sampled had a maximum of $300 \mathrm{~mL}$, which is $10 \%$ of the system volume. Thus, after the profiles were performed a new experimental condition was implemented.

\section{Theoretical}

The efficiencies of total organic matter removal $\left(\varepsilon_{\mathrm{ST}}\right)$ are calculated using Equation (1), and the efficiencies of filtered organic matter removal $\left(\varepsilon_{\mathrm{SF}}\right)$ are calculated using Equation (2). The efficiencies of filtered organic matter removal $(\varepsilon)$ for the profiles along the cycle are calculated using Equation (3). $\mathrm{C}_{\mathrm{SINF}}$ and $\mathrm{C}_{\mathrm{SINF} 0}$ is the filtered organic matter concentration in the influent and in the reactor at the beginning of the cycle (time zero - the organic matter concentration in the reactor after the initial dilution of the influent), respectively.

$$
\begin{aligned}
& \varepsilon_{\mathrm{ST}}(\%)=\frac{\mathrm{C}_{\mathrm{SINF}}-\mathrm{C}_{\mathrm{ST}}}{\mathrm{C}_{\mathrm{SINF}}} \times 100 \\
& \varepsilon_{\mathrm{SF}}(\%)=\frac{\mathrm{C}_{\mathrm{SINF}}-\mathrm{C}_{\mathrm{SF}}}{\mathrm{C}_{\mathrm{SINF}}} \cdot 100 \\
& \varepsilon(\%)=\frac{\mathrm{C}_{\mathrm{SINFO}}-\mathrm{C}_{\mathrm{SF}}}{\mathrm{C}_{\mathrm{SINF} 0}} \cdot 100
\end{aligned}
$$

The applied volumetric organic load (AVOL) is defined as the amount of organic matter that is applied to the reactor per unit time and per volume of medium (gCOD.L$\left.{ }^{1} \cdot \mathrm{d}^{-1}\right)$. For reactors operated in batch mode, AVOL is calculated using Equation (4). The specific applied organic load (ASOL) is defined as the amount of organic matter that is applied to the reactor per unit time and per mass of total volatile solids in the reactor $\left(\mathrm{gCOD} \cdot \mathrm{gTVS}^{-1} \cdot \mathrm{d}^{-1}\right)$. For reactors operated in batch mode, ASOL is calculated using Equation (5).

The removed volumetric organic load $\left(\mathrm{RVOL}_{\mathrm{F}}\right)$ for filtered samples is defined as the amount of organic matter 
removed by the reactor per unit time and per volume of medium in the reactor $\left(\mathrm{gCOD} \cdot \mathrm{L}^{-1} \cdot \mathrm{d}^{-1}\right)$. For reactors operated in batch mode, $\mathrm{RVOL}_{\mathrm{F}}$ is calculated using Equation (6). The specific removed organic load $\left(\mathrm{RSOL}_{\mathrm{F}}\right)$ for filtered samples is defined as the amount of organic matter removed per unit time and per mass of total volatile solids in the reactor $\left(\mathrm{gCOD} \cdot \mathrm{gTVS}^{-1} \cdot \mathrm{d}^{-1}\right)$. For reactors operated in batch mode, $\mathrm{RSOL}_{\mathrm{F}}$ is calculated using Equation (7).

$$
\begin{gathered}
A V O L=\frac{\left(V_{F} \cdot N\right) \cdot C_{S I N F}}{V_{R}} \\
A S O L=\frac{\left(V_{F} \cdot N\right) \cdot C_{S I N F}}{M_{T V S}} \\
R V O L_{F}=\frac{\left(V_{F} \cdot N\right) \cdot\left(C_{S I N F}-C_{S F}\right)}{V_{R}} \\
R_{S O L}=\frac{\left(V_{F} \cdot N\right) \cdot\left(C_{S I N F}-C_{S F}\right)}{M_{T V S}}
\end{gathered}
$$

Productivity (volumetric, VPr, or molar, MPr) is defined by the amount of methane produced per unit time and per usable reactor volume (mL-STP-CH ${ }_{4} \cdot \mathrm{L}^{-3} \cdot \mathrm{d}^{-1}$ or $\left.\mathrm{molCH}_{4} \cdot \mathrm{L}^{-3} \cdot \mathrm{d}^{-1}\right)$, as calculated using Equations (8) and (9). The specific productivity (volumetric, SVPr, or molar, SMPr) is defined as the amount of methane produced per unit time and per mass of total volatile solids in the reactor $\left(\mathrm{mL}-\mathrm{STP}-\mathrm{CH}_{4} \cdot \mathrm{kgTVS}^{-1} \cdot \mathrm{d}^{-1}\right.$ or $\left.\mathrm{molCH}_{4} \cdot \mathrm{kgTVS}^{-1} \cdot \mathrm{d}^{-1}\right)$ and is calculated from Equations (10) and (11).

The volumetric yield of methane produced (mL-STP) per consumed load (gCOD) is defined as the amount of methane produced (in moles) by the amount of organic matter consumed (in mass). The molar volumetric yield of methane can be obtained by replacing the volume of produced methane (mL-STP) in Equation (12) with the amount of methane produced in moles, as found by using Equation (13).

$$
\begin{gathered}
V P r=\frac{N \cdot V_{C H 4-S T P}}{V_{R}} \\
M P r=\frac{N \cdot N_{C H 4}}{V_{R}} \\
S V P r=\frac{N \cdot V_{C H 4-S T P}}{M_{T V S}}
\end{gathered}
$$

$$
\begin{gathered}
S M P r=\frac{N \cdot N_{C H 4}}{M_{T V S}} \\
Y_{V-C H 4 / C O D}=\frac{V_{C H 4-S T P}}{V_{F} \cdot\left(C_{S A F F}-C_{S F}\right)} \\
Y_{M-C H 4 / \mathrm{COD}}=\frac{N_{C H 4}}{V_{F} \cdot\left(C_{S A F F}-C_{S F}\right)}
\end{gathered}
$$

The first-order kinetic model applied was developed by Rodrigues et al. (2004), based on the model of Bagley and Brodkorb (1999). The latter is an adaptation of another model that was proposed by the International Water Association (IWA) and was applied to systems of treatment with activated sludge. In the applied model, which was developed to sequence anaerobic batch reactors, the organic matter degradation process is simplified and divided into two consecutive steps. The first step is when the substrate is converted into total volatile acids, and in the second step, these acids are converted into methane. The model admits the existence of a residual concentration of both substrate and total volatile acids, in which the respective reaction rate tends to zero.

The organic matter degradation pathway is shown as follows, in which a, b and c are stoichiometric coefficients and $\mathrm{k}_{1}$ and $\mathrm{k}_{2}$ are the apparent kinetic parameters (Equation 14).

$$
\begin{gathered}
\mathrm{a} \cdot \mathrm{S} \stackrel{\mathrm{k}_{1}}{\longrightarrow} \mathrm{b} \cdot \mathrm{TVA} \stackrel{\mathrm{k}_{2}}{\longrightarrow} \mathrm{c} \cdot \mathrm{M} \\
r_{S}=k_{1 \cdot S} \cdot\left(C_{S}-C_{S R}\right) \\
r_{T V A}=k_{1 \cdot T V A} \cdot\left(C_{S}-C_{S R}\right)-k_{2 \cdot T V A} \cdot\left(C_{T V A}-C_{T V A R}\right) \\
r_{M}=k_{2 \cdot M} \cdot\left(C_{T V A}-C_{T V A R}\right)
\end{gathered}
$$

The equations of the reaction rate of substrate consumption $\left(\mathrm{r}_{\mathrm{S}}\right)$, the formation of total volatile acids $\left(\mathrm{r}_{\mathrm{TVA}}\right)$ and the formation of methane $\left(\mathrm{r}_{\mathrm{M}}\right)$ are shown in Equations (15) to (17), with $\mathrm{k}_{1 \mathrm{~S}}, \mathrm{k}_{1 \mathrm{TVA}}, \mathrm{k}_{2 \mathrm{TVA}}$ and $\mathrm{k}_{2 \mathrm{M}}$ being the same apparent kinetic parameters, but associated with substrate consumption, total volatile acids formation and methane formation, respectively. $\mathrm{C}_{\mathrm{S}}$ and $\mathrm{C}_{\mathrm{TVA}}$ are the substrate concentrations and the total volatile acids, and $\mathrm{C}_{\mathrm{SR}}$ and $\mathrm{C}_{\mathrm{TVAR}}$ are their respective residual values.

The mass balance of the reactor is shown in Equations (18) to (21). Two distinct conditions of operation must be considered: the first is in fed-batch mode, in which the feeding time is not negligible compared with the total 
cycle length (i.e., $\mathrm{F} \neq 0$ ), and the second is in batch mode, in which the feeding time is negligible (i.e., $\mathrm{F}=0$ ). The values of $\mathrm{C}_{\mathrm{S} 0}, \mathrm{C}_{\mathrm{TVA} 0}, \mathrm{C}_{\mathrm{M} 0}$ and $\mathrm{V}_{0}$ correspond to the initial values of $\mathrm{C}_{\mathrm{S}}, \mathrm{C}_{\mathrm{TVA}}, \mathrm{C}_{\mathrm{M}}$ and $\mathrm{V}$, respectively. The values of $\mathrm{C}_{\mathrm{Sf}}$ and $\mathrm{C}_{\mathrm{TVAf}}$ correspond to the values of feeding of $\mathrm{C}_{\mathrm{S}}$ and $\mathrm{C}_{\mathrm{TVA}}$.

$$
\begin{aligned}
& \frac{d V}{d t}=F \quad t=0 \rightarrow V=V_{0} \\
& \frac{d C_{S}}{d t}=\frac{F}{V} \cdot\left(C_{S f}-C_{S}\right)-r_{S} \quad t=0 \rightarrow C_{S}=C_{S 0} \\
& \frac{d C_{T V A}}{d t}=\frac{F}{V} \cdot\left(C_{T V A f}-C_{T V A}\right)+r_{T V A} \\
& t=0 \rightarrow C_{T V A}=C_{T V A 0}
\end{aligned}
$$

$$
\frac{d C_{M}}{d t}=-\frac{F}{V} \cdot C_{M}+r_{M} \quad t=0 \rightarrow C_{M}=C_{M 0}
$$

Because these are differential equations, Euler's numerical integration method and a constant integration step were applied and programmed in the software Excel $^{\mathbb{R}}$ (Excel) to determine these parameters via Newton's algorithm using the Solver tool in Excel.

The non-specific kinetic parameters $\mathrm{k}_{1 \mathrm{~S}}, \mathrm{k}_{1 \mathrm{TVA}}, \mathrm{k}_{2 \mathrm{TVA}} \mathrm{e}$ $\mathrm{k}_{2 \mathrm{M}}$ are apparent because they encompass effects of mass transport and heat transfer. Specific kinetic parameters are the "non-specific" parameters divided by the biomass concentration $\left(\mathrm{C}_{\mathrm{x}}\right.$ - expressed by the total volatile solids in the reactor, TVS, in the volume of reacting medium) and are represented by $\mathrm{k}_{1 \mathrm{~S}}, \mathrm{k}_{1 \mathrm{TVA}}^{\prime} \mathrm{k}_{2 \mathrm{TVA}}$ and $\mathrm{k}_{2 \mathrm{M}}$. The parameters $\mathrm{C}_{\mathrm{SR}}$ and $\mathrm{C}_{\mathrm{TVAR}}$ correspond only to an estimate of the residual value of the substrate and the volatile acids in the reactor at the end of a cycle. In addition, the kinetic model applied is a simplification of the complex process of anaerobic degradation.

\section{RESULTS AND DISCUSSION}

\section{Analysis of the parameters monitored in the experimental conditions in batch mode $\left(30\right.$ and $\left.45^{\circ} \mathrm{C}\right)$ and fed-batch mode $\left(30^{\circ} \mathrm{C}\right)$}

Table 2 presents the average values of the parameters monitored during all of the experimental conditions. Both the organic matter concentration (COD) and efficiency of removal during the increase in organic load in Conditions $\mathrm{C} 01$ to $\mathrm{C} 08$ (batch $-30^{\circ} \mathrm{C}$ ) showed a significant consumption of organic matter, with the efficiency of removal for filtered samples always greater than $90 \%$.

For Conditions $\mathrm{C} 09$ (fed-batch $-30^{\circ} \mathrm{C}$ ) and $\mathrm{C} 10$ (batch $-45^{\circ} \mathrm{C}$ ), the organic matter concentration (COD) in the effluent increased, with efficiencies of removal for the filtered samples of $88 \%$ and $46 \%$, respectively. The average $\mathrm{pH}$ values in all conditions ( $\mathrm{C} 01$ to $\mathrm{C} 10)$ were in the neutral range (7.2-7.7). The total volatile acids in the influent were consumed during the increase of the organic load (Conditions C01 to C08) and increased with the change in feed strategy and temperature (Conditions C09 and $\mathrm{C} 10)$.

The increase in the organic load also led to a gradual increase in the volumes of biogas per cycle (Conditions $\mathrm{C} 01$ to C08). This result can be explained by the increase in the organic matter (COD) fed because under these conditions a greater amount of substrate that could be converted into biogas was fed to the reactor. In addition, favourable environmental conditions existed for the stability of the process. The maximum, the mean and minimum volumes of $\mathrm{CH}_{4}$ produced were 2767,1169 and $107 \mathrm{~mL}-\mathrm{STP}-\mathrm{CH}_{4}$. $\mathrm{Cycle}^{-1}$, respectively. However, there were decreases in the volumes of biogas that were produced per cycle with changes in the feed strategy and temperature (conditions $\mathrm{C} 09$ and $\mathrm{C} 10$ ), which resulted in volumes of 2297 and 785 $\mathrm{mL}-\mathrm{STP}-\mathrm{CH}_{4} \cdot \mathrm{Cycle}^{-1}$, respectively.

Table 3 presents the performance indicators for the increase in organic load (conditions $\mathrm{C} 01$ to $\mathrm{C} 08$ ), the change in feed strategy from batch mode to fed-batch mode and the increase in temperature from $30^{\circ} \mathrm{C}$ to $45^{\circ} \mathrm{C}$ (conditions $\mathrm{C} 09$ and $\mathrm{C} 10$ ). Shading indicates the proportion of the magnitudes of parameters in the same line. $\mathrm{Y}_{\mathrm{E}} / \mathrm{Y}_{\mathrm{T}}$ is the ratio of the experimental yield, both molar $(\mathrm{M})$ and volumetric $(\mathrm{V})$, to the theoretical yield of $15.63 \mathrm{mmolCH}_{4}$. $\mathrm{gCOD}^{-1}$ or $350 \mathrm{mLCH}_{4}-\mathrm{STP}_{\mathrm{gCOD}}{ }^{-1}$. SMPr and SVPr are the specific molar and volumetric productivity indicators, respectively, and $\mathrm{X}_{\mathrm{CH} 4}$ is the percentage of methane in biogas.

For the conditions in batch mode at $30^{\circ} \mathrm{C}(\mathrm{C} 01$ to C08), Table 3 shows that there is a general tendency for the indicators to increase with an increase in organic load, and Condition $\mathrm{C} 07$ presented the best results. The yield indicator $\mathrm{Y}_{\mathrm{M}-\mathrm{CH} / \mathrm{COD}}$ shows that, overall, a greater number of $\mathrm{CH}_{4}$ molecules were produced from the same quantity of consumed organic matter, i.e., the system became more efficient by increasing the organic load. Figure 2 shows a tendency to reach a maximum; as a result, using the fitted equation shown, the maximum yield was $13.7 \mathrm{mmolCH}_{4}$. $\mathrm{gCOD}^{-1}$, corresponding to an AVOL of $7.50 \mathrm{gCOD} \cdot \mathrm{L}^{-1} \cdot \mathrm{d}^{-1}$ (batch at $30^{\circ} \mathrm{C}$ ). This yield corresponds to $88 \%$ of the theoretical yield. In addition, the methane productivity increased with the increase in organic load. The maximum molar (MPr) reached was $123.4 \mathrm{molCH}_{4} \cdot \mathrm{m}^{-3} \cdot \mathrm{d}^{-1}$, and the volumetric (VPr) of $2767 \mathrm{~mL}-\mathrm{STP}-\mathrm{CH}_{4} \cdot \mathrm{L}^{-1} \cdot \mathrm{d}^{-1}$. Figure 2 shows a tendency of increasing productivity towards this maximum in an AVOL of $10.1 \mathrm{gCOD} \cdot \mathrm{L}^{-1} \cdot \mathrm{d}^{-1}$. 
Effects of Organic Loading, Feed Strategy and Temperature

Table 2. Experimental protocol and parameters monitored in the effluent and the organic loads for all experimental conditions.

\begin{tabular}{|c|c|c|c|c|c|c|c|c|c|c|c|}
\hline Parameter & Condition & $\mathrm{C01}$ & $\mathrm{CO2}$ & $\mathrm{C03}$ & $\mathrm{C04}$ & $\mathrm{C05}$ & $\mathrm{C06}$ & $\mathrm{C07}$ & $\mathrm{CO8}$ & C09 & $\mathrm{C10}$ \\
\hline $\mathrm{T}$ & $\left({ }^{\circ} \mathrm{C}\right)$ & 30 & 30 & 30 & 30 & 30 & 30 & 30 & 30 & 30 & 45 \\
\hline $\mathrm{C}_{\mathrm{INF}}$ & $\left(\mathrm{mgCOD} . \mathrm{L}^{-1}\right)$ & 1000 & 2000 & 3000 & 4000 & 5000 & 6000 & 8000 & 10000 & 10000 & 10000 \\
\hline Feed strategy & & $\mathrm{B}$ & $\mathrm{B}$ & $\mathrm{B}$ & $\mathrm{B}$ & $\mathrm{B}$ & $\mathrm{B}$ & $\mathrm{B}$ & B & FB & $\mathrm{B}$ \\
\hline $\mathrm{C}_{\mathrm{ST}}$ & $\left(\mathrm{mgCOD} . \mathrm{L}^{-1}\right)$ & 125 & 219 & 314 & 351 & 167 & 191 & 254 & 261 & 1150 & 5204 \\
\hline $\mathrm{C}_{\mathrm{SF}}$ & $\left(\mathrm{mgCOD} \cdot \mathrm{L}^{-1}\right)$ & 109 & 167 & 286 & 384 & 129 & 154 & 224 & 235 & 1025 & 5036 \\
\hline$\varepsilon_{\mathrm{ST}}$ & $(\%)$ & 89 & 89 & 90 & 92 & 97 & 97 & 97 & 97 & 88 & 46 \\
\hline$\varepsilon_{\mathrm{SF}}$ & $(\%)$ & 90 & 92 & 91 & 91 & 98 & 98 & 97 & 98 & 90 & 48 \\
\hline $\mathrm{pH}$ & $\mathrm{u}$ & 7.20 & 7.44 & 7.52 & 7.70 & 7.43 & 7.62 & 7.69 & 7.72 & 7.85 & 7.64 \\
\hline TVA & $\left(\mathrm{mgHAc} . \mathrm{L}^{-1}\right)$ & 25 & 33 & 63 & 57 & 38 & 66 & 82 & 73 & 616 & 2591 \\
\hline BA & $\left(\mathrm{mgCaCO}_{3} \cdot \mathrm{L}^{-1}\right)$ & 492 & 967 & 1383 & 1819 & 1683 & 1982 & 2511 & 3383 & 4055 & 2367 \\
\hline TS & $\left(\mathrm{mg} \cdot \mathrm{L}^{-1}\right)$ & 862 & 1807 & 2365 & 2793 & 2361 & 2994 & 4138 & 4958 & 7532 & 9809 \\
\hline TDS & $\left(\mathrm{mg} \cdot \mathrm{L}^{-1}\right)$ & 832 & 1749 & 2317 & 2739 & 2323 & 2958 & 4100 & 4897 & 7331 & 9641 \\
\hline DVS & $\left(\mathrm{mg} \cdot \mathrm{L}^{-1}\right)$ & 347 & 583 & 541 & 433 & 426 & 630 & 969 & 1150 & 1693 & 3271 \\
\hline $\mathrm{M}_{\mathrm{TVS}}$ & (g) & 41.5 & 41.2 & 44.4 & 58.6 & 42.5 & 54.9 & 50.4 & 64.7 & 82.1 & 61.3 \\
\hline $\mathrm{C}_{\mathrm{X}}$ & $\left(\mathrm{g} . \mathrm{L}^{-1}\right)$ & 13.8 & 13.7 & 14.8 & 19.5 & 14.2 & 18.3 & 16.8 & 21.6 & 27.4 & 20.4 \\
\hline $\mathrm{C}_{\mathrm{X}}$ & (g.gsupport ${ }^{-1}$ ) & 0.76 & 0.82 & 0.88 & 0.95 & 0.80 & 1.21 & 1.16 & 1.72 & 1.86 & 1.25 \\
\hline $\mathrm{V}_{\mathrm{CH} 4}$ & $\left(\mathrm{mLCH}_{4} \cdot \mathrm{cycle}^{-1}\right)$ & 107 & 352 & 627 & 911 & 1424 & 1815 & 2403 & 2767 & 2297 & 785 \\
\hline AVOL & $\left(\mathrm{gCOD} \cdot \mathrm{L}^{-1} \cdot \mathrm{d}^{-1}\right)$ & 1.09 & 2.09 & 3.01 & 4.12 & 5.16 & 6.19 & 8.18 & 10.07 & 9.67 & 10.31 \\
\hline RVOL & $\left(\mathrm{gCOD} \cdot \mathrm{L}^{-1} \cdot \mathrm{d}^{-1}\right)$ & 0.98 & 1.92 & 2.72 & 3.74 & 5.03 & 6.04 & 7.96 & 9.83 & 8.67 & 4.90 \\
\hline ASOL & $\left(\right.$ gCOD.gSVT $\left.{ }^{-1} \cdot \mathrm{d}^{-1}\right)$ & 0.08 & 0.15 & 0.20 & 0.21 & 0.36 & 0.34 & 0.49 & 0.47 & 0.35 & 0.50 \\
\hline RSOL & $\left(\mathrm{gCOD} \cdot g \mathrm{SVT}^{-1} \cdot \mathrm{d}^{-1}\right)$ & 0.07 & 0.14 & 0.18 & 0.19 & 0.35 & 0.33 & 0.47 & 0.46 & 0.32 & 0.24 \\
\hline
\end{tabular}

(1) The cycle length time $\left(\mathrm{t}_{\mathrm{C}}\right)$ was $8 \mathrm{~h}(3$ cycle/d) for all experimental conditions.

(2) Feed strategy was in batch (B, feeding time of $10 \mathrm{~min}, \mathrm{t}_{\mathrm{F}} / \mathrm{t}_{\mathrm{C}}=2 \%$ ) or fed-batch (FB, $\left.240 \mathrm{~min}, \mathrm{t}_{\mathrm{F}} / \mathrm{t}_{\mathrm{C}}=50 \%\right)$.

(3) The average percentage experimental error and average number of samples were, respectively, $\mathrm{C}_{\mathrm{ST}} 14.3 \%$ ( 8 samples);

$\mathrm{C}_{\mathrm{SF}} 16.6 \%$ (8 samples); $\varepsilon_{\mathrm{ST}} 2.1 \%$ (8 samples); $\varepsilon_{\mathrm{SF}} 2.1 \%$ (8 samples); $\mathrm{pH} 2.5 \%$ (9 samples); TVA $22.8 \%$ (8 samples);

BA $9.0 \%$ (8 samples); TS $8.7 \%$ (4 samples).

There are two factors that can cause the increase in productivity with the increase of organic load (or increase in concentration) under favourable environmental conditions: (i) the fact that the increase in organic load corresponds to the increase in the number of molecules that can be converted to methane; and (ii) an improvement in the reaction rate of substrate consumption by microorganisms. For organic loads higher than that experienced, if the yield maintains its decreasing pattern, then the methane production must decrease as well because the increase in substrate concentration is insufficient to maintain the rise in productivity.

With regard to the indicator $\mathrm{Y}_{\mathrm{M}-\mathrm{CH} / \mathrm{COD}}$, in Condition C08 (batch at $30^{\circ} \mathrm{C}$, AVOL of 10.0 gCOD. $\mathrm{L}^{-1} \cdot \mathrm{d}^{-1}$ ), the yield was $12.6 \mathrm{mmolCH}_{4} \cdot \mathrm{gCOD}^{-1}$; in Condition $\mathrm{C} 09$ (fed-batch at $30^{\circ} \mathrm{C}$, AVOL of $10.0 \mathrm{gCOD} \cdot \mathrm{L}^{-1} \cdot \mathrm{d}^{-1}$ ), it was $11.8 \mathrm{mmolCH}_{4} \cdot \mathrm{gCOD}^{-1}$; and in Condition $\mathrm{C} 10$ (batch at $45^{\circ} \mathrm{C}$, AVOL of $\left.10.0 \mathrm{gCOD} \cdot \mathrm{L}^{-1} \cdot \mathrm{d}^{-1}\right)$, it was $7.1 \mathrm{mmolCH}_{4}$. $\mathrm{gCOD}^{-1}$. For the best experimental condition (Condition $\mathrm{C} 07$ - batch at $30^{\circ} \mathrm{C}$, AVOL of $\left.8.0 \mathrm{gCOD} \cdot \mathrm{L}^{-1} \cdot \mathrm{d}^{-1}\right)$, the yield was $13.5 \mathrm{mmolCH}_{4} \cdot \mathrm{gCOD}^{-1}$. The ratios between the experimental yields for Conditions $\mathrm{C} 07, \mathrm{C} 08, \mathrm{C} 09$ and $\mathrm{C} 10$ and the maximum theoretical yield were $86 \%, 80 \%$, $76 \%$ and $46 \%$, respectively. For methane productivity, with a change in feed strategy to fed-batch mode and the rise in temperature to $45^{\circ} \mathrm{C}$, fewer molecules of methane were produced by the same volume of reacting medium.
The maximum molar productivity achieved was in batch operation (Table 3) compared with fed-batch operation, with $102.5 \mathrm{molCH}_{4} \cdot \mathrm{m}^{-3} \cdot \mathrm{d}^{-1}$, which corresponded to a volume of $2297 \mathrm{~mL}-\mathrm{STP}-\mathrm{CH}_{4} \cdot \mathrm{L}^{-1} \cdot \mathrm{d}^{-1}$ and, with $45^{\circ} \mathrm{C}$ with $35.0 \mathrm{molCH}_{4} \cdot \mathrm{m}^{-3} \cdot \mathrm{d}^{-1}$, which corresponded to a volume of $785 \mathrm{~mL}-\mathrm{STP}-\mathrm{CH}_{4} \cdot \mathrm{L}^{-1} \cdot \mathrm{d}^{-1}$. This effect was probably due to a high reaction rate in batch mode in comparison to the dilution which occurred in fed-batch mode.

From Figure 2, one can observe that in Condition $\mathrm{C} 08$ (AVOL of $10.0 \mathrm{gCOD} \cdot \mathrm{L}^{-1} \cdot \mathrm{d}^{-1}$, batch at $30^{\circ} \mathrm{C}$ ), the process of degradation likely reached a maximum threshold of methane productivity, but was already under the maximum yield. The transition to fed-batch in Condition C09 (AVOL of $10.0 \mathrm{gCOD} \cdot \mathrm{L}^{-1} \cdot \mathrm{d}^{-1}$, fed-batch at $30^{\circ} \mathrm{C}$ ) was not sufficient to improve the yield and production of methane because the environmental condition was possibly close to the maximum threshold.

In addition to the decrease in the volume of biogas when the feed strategy was changed to fed-batch mode (Condition $\mathrm{C} 08$ to $\mathrm{C} 09$ ), when the temperature increased from $30^{\circ} \mathrm{C}$ to $45^{\circ} \mathrm{C}$ (Condition $\mathrm{C} 08$ to $\mathrm{C} 10-\mathrm{AVOL}$ of $10.0 \mathrm{gCOD} . \mathrm{L}^{-1} \cdot \mathrm{d}^{-1}$ and batch mode), this volume reduced drastically. This decrease could be due to the biomass loss observed during Condition C10, as indicated by an increase in total volatile solids in the effluent during the experiment (2254 to 3596 mgTVS.L $\mathrm{L}^{-1}$ ). The biomass loss could also be perceived visually from the grey/black colour of the material retained by the filter during effluent filtering. 
Table 4 present the peaks of concentration of the intermediate compounds produced in a cycle for each experimental condition. Acetone and methanol concentration were below the limit of detection of the chromatographic method employed. The table indicates that, for an increasing organic load, in general, the following acids were prevalent: acetic, propionic and butyric. The maximum concentration of acetic and propionic acids in a cycle increased with increasing organic load, while the maximum concentration of butyric acid rose until Condition $\mathrm{C} 03$ and then decreased in the subsequent conditions. Ethanol concentration was always low or lower than the limit of detection of until Condition C04 and then increased in Condition 05 due to the use of vinasse that had been previously frozen, which prevented ethanol degradation.

The change in feed strategy from batch mode to fedbatch mode (Condition C08) caused a decrease in the peaks of concentration in all intermediate compounds. This result was due to the characteristics of the fed-batch feed strategy because the influent was dosed in low quantities, which led to a decrease in the intermediate concentration.

Table 3. Performance indicators for all experimental conditions.

\begin{tabular}{|c|c|c|c|c|c|c|c|c|c|c|c|}
\hline \multirow{2}{*}{ Parameter } & & C01 & $\mathrm{CO2}$ & $\mathrm{C03}$ & $\mathrm{C04}$ & $\mathrm{C05}$ & $\mathrm{C06}$ & $\mathrm{C07}$ & $\mathrm{C08}$ & C09 & $\mathbf{C 1 0}$ \\
\hline & & \multicolumn{8}{|c|}{ Increase in Applied Volumetric Organic Load (AVOL) } & Fed-Batch & $45^{\circ} \mathrm{C}$ \\
\hline AVOL & $\left(\mathrm{gCOD} \cdot \mathrm{L}^{-1} \cdot \mathrm{d}^{-1}\right)$ & 1.1 & 2.1 & 3.0 & 4.1 & 5.2 & 6.2 & 8.2 & 10.1 & 9.7 & 10.3 \\
\hline $\mathrm{X}_{\mathrm{CH} 4}$ & $(\%)$ & 67 & 76 & 76 & 76 & 79 & 78 & 79 & 78 & 73 & 65 \\
\hline $\mathrm{X}_{\mathrm{CO} 2}$ & $(\%)$ & 33 & 24 & 24 & 24 & 21 & 22 & 21 & 22 & 27 & 35 \\
\hline $\mathrm{Y}_{\mathrm{M}-\mathrm{CH} 4 / \mathrm{COD}}$ & $\left(\mathrm{mmolCH}_{4} \cdot \mathrm{gCOD}^{-1}\right)$ & 4.9 & 8.2 & 10.3 & 10.9 & 12.6 & 13.4 & 13.5 & 12.6 & 11.8 & 7.1 \\
\hline $\mathrm{Y}_{\mathrm{V}-\mathrm{CH} 4 / \mathrm{COD}}$ & $\left(\mathrm{mL}^{-\mathrm{STPCH}_{4}} \cdot \mathrm{gCOD}^{-1}\right)$ & 109 & 184 & 230 & 244 & 283 & 301 & 302 & 281 & 265 & 160 \\
\hline $\mathrm{Y}_{\mathrm{E}} / \mathrm{Y}_{\mathrm{T}}$ & $(\%)$ & 31.2 & 52.5 & 65.8 & 69.6 & 80.7 & 85.8 & 86.2 & 80.3 & 75.6 & 45.7 \\
\hline $\mathrm{MPr}$ & $\left(\mathrm{molCH}_{4} \cdot \mathrm{m}^{-3} \cdot \mathrm{d}^{-1}\right)$ & 4.8 & 15.7 & 28.0 & 40.7 & 63.5 & 81.0 & 107.2 & 123.4 & 102.5 & 35.0 \\
\hline SMPr & $\left(\mathrm{molCH}_{4} \cdot \mathrm{kgTVS}^{-1} \cdot \mathrm{d}^{-1}\right)$ & 0.3 & 1.1 & 1.9 & 2.1 & 4.5 & 4.4 & 6.4 & 5.7 & 3.7 & 1.7 \\
\hline $\operatorname{VPr}$ & $\left(\mathrm{mL}-\mathrm{STPCH}_{4} \cdot \mathrm{L}^{-1} \cdot \mathrm{d}^{-1}\right)$ & 107 & 352 & 627 & 911 & 1424 & 1815 & 2403 & 2767 & 2297 & 785 \\
\hline SVPr & $\left(\mathrm{mL}_{-} \mathrm{STPCH}_{4} \cdot \mathrm{gTVS}^{-1} \cdot \mathrm{d}^{-1}\right)$ & 7.7 & 25.7 & 42.3 & 46.6 & 100.4 & 99.2 & 143.0 & 128.3 & 83.9 & 38.4 \\
\hline
\end{tabular}

(1) Theoretical yield of methane from consumed COD: 15.6 mmolCH $_{4} \mathrm{gCOD}^{-1}$ (molar) or $350 \mathrm{mLCH}_{4}-\mathrm{STP}_{\mathrm{gCOD}} \mathrm{gCol}^{-1}$ (volumetric).
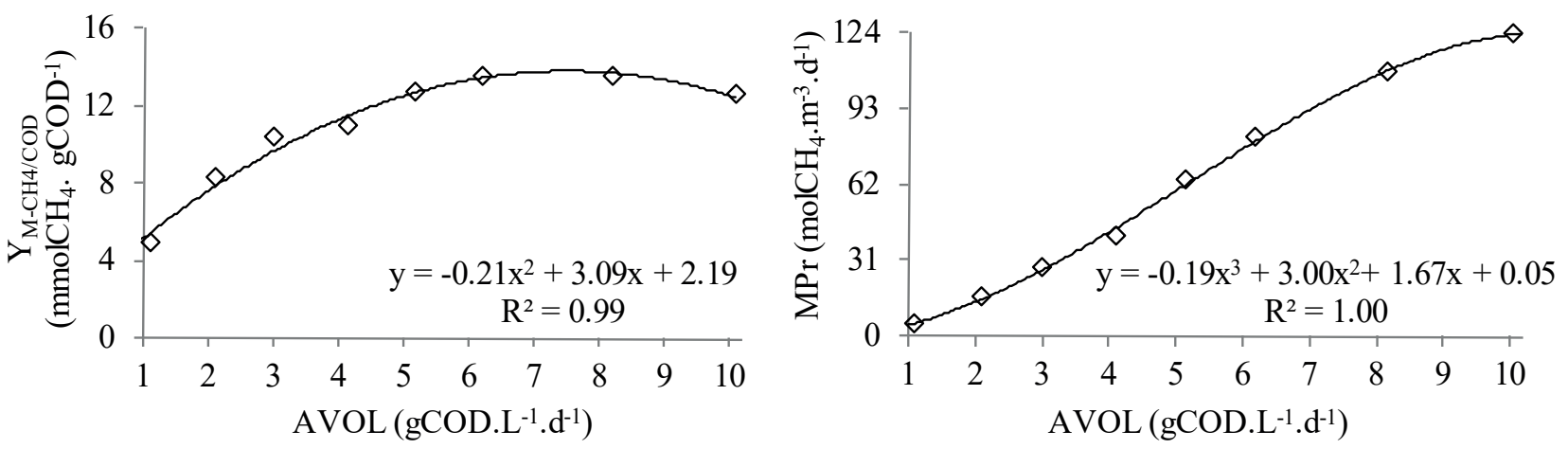

Figure 2. Evolution of the yield (YM-CH4/COD) and molar methane productivity indicators (MPr) with the applied volumetric organic load (AVOL).

Table 4. Maximum concentrations of the intermediate compounds (mg.L-1) in a cycle for all experimental conditions *.

\begin{tabular}{|c|c|c|c|c|c|c|c|}
\hline & Condition & $\mathrm{EtOH}$ & HAc & HPr & HBut & $\mathrm{HVa}$ & $\mathrm{HCa}$ \\
\hline \multirow{8}{*}{$\begin{array}{c}\text { Increasing } \\
\text { AVOL }\end{array}$} & $\mathrm{C} 01$ & 42 & 114 & 29 & 17 & 13 & 13 \\
\hline & $\mathrm{C} 02$ & 0 & 116 & 65 & 3 & 14 & 16 \\
\hline & $\mathrm{C} 03$ & 0 & 164 & 97 & 46 & 16 & 17 \\
\hline & $\mathrm{C} 04$ & 0 & 186 & 103 & 44 & 32 & 21 \\
\hline & $\mathrm{C} 05$ & 340 & 477 & 102 & 12 & 23 & 27 \\
\hline & $\mathrm{C} 06$ & 466 & 711 & 123 & 15 & 19 & 16 \\
\hline & $\mathrm{C} 07$ & 529 & 865 & 168 & 19 & 20 & 17 \\
\hline & $\mathrm{C} 08$ & 491 & 1207 & 176 & 9 & 13 & 16 \\
\hline Fed-Batch & $\mathrm{C} 09$ & 89 & 367 & 80 & 10 & 19 & 0 \\
\hline $45^{\circ} \mathrm{C}$ & $\mathrm{C} 10$ & 50 & 5189 & 1351 & 14 & 15 & 15 \\
\hline
\end{tabular}

$*<$ Limit of detection estimated as $3 \mathrm{mg} \cdot \mathrm{L}^{-1}$. 
In Condition $\mathrm{C} 10$, at $45^{\circ} \mathrm{C}$, propionic acid predominated in relation to acetic acid. Thus, it is possible that acetogenic microorganisms were inhibited by temperature, thereby causing a conversion of propionic to acetic acid, which indicates a deviation in the main acetic metabolic pathway.

\section{Analysis of the profiles along a cycle in batch mode $\left(30^{\circ} \mathrm{C}\right)$}

Figures 3 and 4 show the profiles of organic matter concentration, TVA and methane for $\mathrm{C} 01$ to $\mathrm{C} 08$ (increasing in organic load) and C09 and C10 (change in feed strategy and temperature), as well as the model fitted to the experimental data. The visual analysis leads to the conclusion that the model could represent the tendencies of production and consumption of the presented compounds.

In Table 5, the first-order kinetic parameters for each experimental condition are presented, and in Figure 5, these parameters are presented for Conditions C01 to $\mathrm{C} 08$ as a function of organic load. In general, a similar tendency is found for both specific and non-specific kinetic parameters, which indicates that the changes in the environmental conditions are influenced in a similar manner by the individuals and the microbial population.

By analysing $\mathrm{k}_{1 \mathrm{~S}}$ and $\mathrm{k}_{1 \mathrm{~S}}$ (Figure 5a), note that an increase in organic load led to a decrease in the organic matter consumption reaction rate in the transition of Condition C01 to C02. Next, considering $\mathrm{k}_{1 \mathrm{~s}}$, a tendency to increase with the increase in organic load (Conditions $\mathrm{C} 02$ to $\mathrm{C} 08$ ) is observed, whereas for $\mathrm{k}_{1 \mathrm{~S}}$, a tendency for the reaction rate to decrease is observed. The $\mathrm{k}_{2 \mathrm{M}}$ and $\mathrm{k}_{2 \mathrm{M}}$ generally presented a tendency to increase with load (Figure 5b). The same tendency can be observed for the molar productivity of methane (MPr) (Table 3), i.e., the increase in the number of molecules produced in relation to the liquid medium is a result of the increase of the average reaction rate of methane production $\left(\mathrm{C}_{\text {Mave }}\right)$ observed in Conditions $\mathrm{C} 01$ to $\mathrm{C} 08$.

Considering the kinetic equation of the methane production rate, $\mathrm{r}_{\mathrm{M}}=\mathrm{k}_{2 \mathrm{M}}\left(\mathrm{C}_{\mathrm{TVA}}-\mathrm{C}_{\mathrm{TVAR}}\right)$, the increase in this reaction rate between the experimental conditions was due to both the increase of the average concentration of TVA, or the increase in substrate concentration, and the improvement in the production of molecules of methane by microorganisms, i.e., by the increase in the parameter $\mathrm{k}_{2 \mathrm{~m}}\left(\right.$ or k' $\left.{ }_{2 \mathrm{~m}}\right)$.

The parameters $\mathrm{k}_{1 \mathrm{TVA}}\left(\right.$ or $\mathrm{k}_{1 \mathrm{TVA}}$ ) and $\mathrm{k}_{2 \mathrm{TVA}}\left(\right.$ or $\left.\mathrm{k}^{\prime}{ }_{2 \mathrm{TVA}}\right)$ define, respectively, the rate of production and consumption of TVA at each point of the profiles of TVA and of $\mathrm{C}_{\mathrm{S}}$. Based on the kinetic equation of rate of production or consumption of TVA $\left[\mathrm{r}_{\mathrm{TVA}}^{\prime}=\mathrm{k}_{1 \mathrm{TVA}}\left(\mathrm{C}_{\mathrm{S}}-\mathrm{C}_{\mathrm{SR}}\right)-\mathrm{k}_{2 \mathrm{TVA}}\left(\mathrm{C}_{\mathrm{TVA}}-\mathrm{C}_{\mathrm{ATVA}}\right)\right]$, the production term is due to the constant $\mathrm{k}_{1 \mathrm{TVA}}$ and concentration $\mathrm{C}_{\mathrm{S}}$, whereas the consumption term is due to the constant $\mathrm{k}_{2 \mathrm{TVA}}$ and the concentration $\mathrm{C}_{\mathrm{TVA}}$.

Figure $5 \mathrm{e}$ shows that the parameter $\mathrm{k}^{\prime}{ }_{\text {TVA }}$ was higher than $\mathrm{k}^{\prime}{ }_{\mathrm{ITV}}$, thus revealing that consumption of acids was always higher than their production. The same can be said with regard to the non-specific parameters. Further, the increase in organic load led to a decrease in $\mathrm{k}_{2 \mathrm{TVA}}$ relative to $\mathrm{k}^{\prime}{ }_{1 \mathrm{TVA}}$ so that the parameter values became similar in Condition $08\left(\mathrm{k}^{\prime}{ }_{\text {ITVA }}=0.0433 \mathrm{mg}^{-1} \cdot \mathrm{L} \cdot \mathrm{h}^{-1}\right.$ and $\left.\mathrm{k}_{\text {2TVA }}=0.0585 \mathrm{mg}^{-1} \cdot \mathrm{L} \cdot \mathrm{h}^{-1}\right)$. Thus, if this tendency is maintained in organic loads greater than that experienced when varying the influent concentration, the consumption term can eventually be overcome by the production term, ultimately leading the process to collapse due to the accumulation of acids.

These results are coherent with the indicators of productivity and yield of methane presented in Table 3. Further, they confirm that the process of degradation improved with the increase in organic load (only by increasing concentration) and validate the hypothesis that the process achieved a maximum level of degradation.

\section{Analysis of the profiles along a cycle in fed-batch mode $\left(45^{\circ} \mathrm{C}\right)$}

For Conditions C08, C09 and C10, based on an analysis of $\mathrm{k}_{1 \mathrm{~S}}$ and $\mathrm{k}_{1 \mathrm{~S}}$, Table 4 indicates that the reaction rate of substrate consumption decreased in fed-batch mode and when the temperature rose (transition between Conditions $\mathrm{C} 08$ and $\mathrm{C} 09$ and between $\mathrm{C} 08$ and $\mathrm{C} 10$ ). Regarding the parameters $\mathrm{k}_{2 \mathrm{M}}$ and $\mathrm{k}_{2 \mathrm{M}}$, the change in feed strategy led to an increase in methane production rate, with the kinetic parameters for Condition C09 being similar to those of Condition $\mathrm{C} 08$ in batch mode. However, the change in temperature led to a decrease in the rate of methane production.

Using the kinetic equation to determine the variation in TVA for fed-batch mode, $\left[\mathrm{C}_{\mathrm{TVA}}{ }^{\prime}=(\mathrm{F} / \mathrm{V})\right.$ $\left.\left(\mathrm{C}_{\mathrm{TVAf}}-\mathrm{C}_{\mathrm{TVA}}\right)+\mathrm{k}_{1 \mathrm{TVA}}\left(\mathrm{C}_{\mathrm{S}}-\mathrm{C}_{\mathrm{SR}}\right)-\mathrm{k}_{2 \mathrm{TVA}}\left(\mathrm{C}_{\mathrm{TVA}}-\mathrm{C}_{\mathrm{TVAR}}\right)\right]$, it can be observed that the accumulation term is due to the constant $\mathrm{k}_{1 \mathrm{TVA}}$, the concentration $\mathrm{C}_{\mathrm{S}}$ and the TVA that are in the feed, whereas the consumption term is due to the constant $\mathrm{k}_{2 \mathrm{TVA}}$ and the concentration $\mathrm{C}_{\mathrm{TVA}}$. For fed-batch mode, because $\mathrm{k}_{2 \mathrm{TVA}}\left(\right.$ or $\mathrm{k}^{\prime}{ }_{2 \mathrm{VVA}}$ ) was higher than $\mathrm{k}_{1 \mathrm{TVA}}$ (or $\mathrm{k}_{\text {1TVA }}$ ), the microorganisms consumed more TVA than was produced. Thus, the accumulation of TVA observed in Figure 4 indicates that microorganisms were not able to consume TVA at a rate higher/equal to the rate at which TVA entered the reactor. The main TFA that enters the reactor is acetate, but Table 4 shows that propionate was the main intermediate that accumulated $(\sim 1350 \mathrm{mg} / \mathrm{L})$ at $45^{\circ} \mathrm{C}$; therefore, in this condition TVA were consumed at rates slower than they were produced.

In general, kinetic parameters for increasing temperatures indicate that the process as a whole was slower than observed at $30^{\circ} \mathrm{C}$. Due to this increase, environmental conditions became unfavourable for some species of microorganisms, which gave privilege to species 

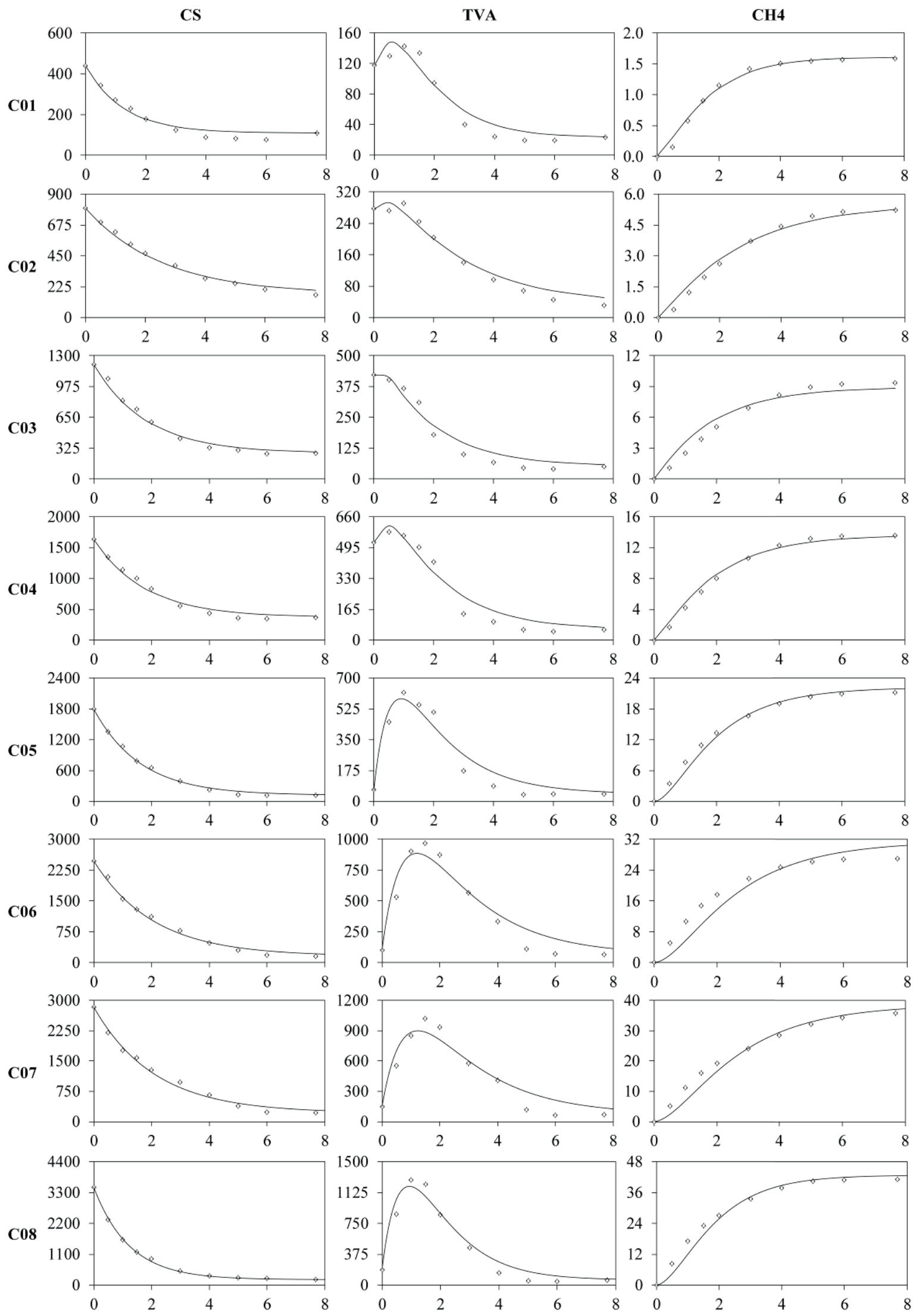

Figure 3. Model fitting (line) to experimental data (dots) for the profiles ( $8 \mathrm{~h}$ cycle time) of organic matter $(\mathrm{CS})$, $\mathrm{TVA}$ and $\mathrm{CH}_{4}$ for Conditions $\mathrm{C} 01$ to $\mathrm{C} 08$ 

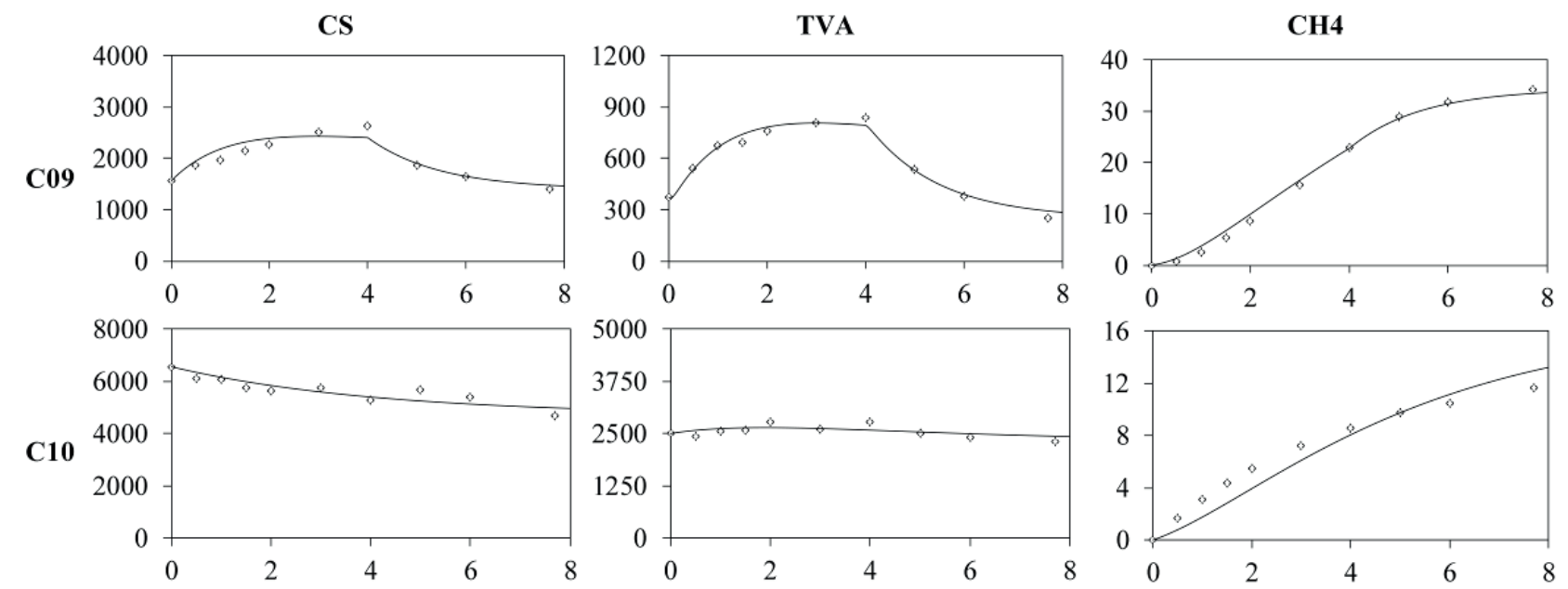

Figure 4. Model fitting (line) to experimental data (dots) for the profiles (cycle time of $8 \mathrm{~h}$ ) of organic matter (CS), $\mathrm{TVA}_{\text {and }} \mathrm{CH}_{4}$ for Conditions $\mathrm{C} 09$ and $\mathrm{C} 10$

Table 5. Kinetic parameters for all experimental conditions.

\begin{tabular}{|c|c|c|c|c|c|c|c|c|c|c|}
\hline & \multicolumn{8}{|c|}{ Increase in Applied Volumetric Organic Load (AVOL) } & $\begin{array}{c}\mathrm{C} 09 \\
\text { Fed-Batch }\end{array}$ & $\begin{array}{l}\mathrm{C} 10 \\
45^{\circ} \mathrm{C}\end{array}$ \\
\hline $\mathrm{C}_{\mathrm{Sf}}$ & - & - & - & - & - & - & - & - & 10251 & - \\
\hline $\mathrm{C}_{\mathrm{S} 0}$ & 438 & 797 & 1205 & 1633 & 1800 & 2473 & 2839 & 3496 & 1559 & 6559 \\
\hline $\mathrm{C}_{\text {TVAf }}$ & - & - & - & - & - & - & - & - & 2026 & - \\
\hline $\mathrm{C}_{\text {TVA } 0}$ & 118 & 276 & 422 & 525 & 65 & 99 & 147 & 188 & 375 & 2500 \\
\hline $\mathrm{C}_{\mathrm{SR}}$ & 109 & 167 & 270 & 370 & 121 & 155 & 216 & 197 & 1400 & 4700 \\
\hline $\mathrm{C}_{\text {TVAR }}$ & 23.0 & 32.0 & 50.0 & 55.0 & 42.0 & 63.0 & 72.0 & 63.0 & 250.0 & 2300.0 \\
\hline $\mathrm{k}_{1 \mathrm{~S}}$ & 0.784 & 0.387 & 0.548 & 0.560 & 0.617 & 0.482 & 0.477 & 0.816 & 0.693 & 0.245 \\
\hline $\mathrm{k}_{1 \mathrm{TVA}}$ & 0.831 & 1.007 & 1.852 & 1.177 & 0.977 & 0.808 & 0.675 & 0.934 & 8.803 & 0.162 \\
\hline $\mathrm{k}_{2 \mathrm{TVA}}$ & 1.450 & 2.108 & 4.028 & 2.102 & 1.728 & 1.273 & 1.182 & 1.261 & 16.50 & 0.556 \\
\hline $\mathrm{k}_{2 \mathrm{M}}$ & 0.316 & 0.374 & 0.612 & 0.551 & 0.828 & 0.614 & 0.725 & 0.830 & 0.860 & 0.391 \\
\hline $\mathrm{k}_{1 \mathrm{~S}}^{\prime}$ & 0.057 & 0.028 & 0.037 & 0.029 & 0.044 & 0.026 & 0.028 & 0.038 & 0.025 & 0.012 \\
\hline $\mathrm{k}_{1 \mathrm{TVA}}^{\prime}$ & 0.060 & 0.073 & 0.125 & 0.060 & 0.069 & 0.044 & 0.040 & 0.043 & 0.322 & 0.008 \\
\hline $\mathrm{k}_{2 \mathrm{TVA}}$ & 0.105 & 0.154 & 0.272 & 0.108 & 0.122 & 0.070 & 0.070 & 0.058 & 0.603 & 0.027 \\
\hline $\mathrm{k}_{2 \mathrm{M}}^{\prime}$ & 0.023 & 0.027 & 0.041 & 0.028 & 0.060 & 0.034 & 0.043 & 0.038 & 0.031 & 0.019 \\
\hline
\end{tabular}

(1) Organic matter concentrations, biomass and solids in $\mathrm{mg} \cdot \mathrm{L}^{-1}$;

(2) Kinetic parameters in h-1 (non-specific) and $\mathrm{mg}^{-1} \cdot \mathrm{L} \cdot \mathrm{h}^{-1}$ (specific).

that were better adapted. The temperature change to $45^{\circ} \mathrm{C}$ can be considered abrupt because there was insufficient time for biomass adaptation. Environmental conditions became severe because the reactor was subjected to a change in temperature at a high applied organic load.

At the end of Condition C09, microbial analysis was performed. The predominance of methanogenic bacilli can be observed, and their presence demonstrates that environmental conditions favourable to methanogens were achieved. Methanosaeta was also detected, which is responsible for the assimilation of acetate (Garcia et al., 2000). The adherence of this microorganism could be favoured by the greater surface area created by the higher sponge porosity.

\section{Comparison to other studies}

TThe studies of Mockaitis et al. (2006), Selma et al. (2010), Lovato et al. (2012) and Silva et al. (2013) refer to the production of methane in Anaerobic Sequencing Batch 
(a)

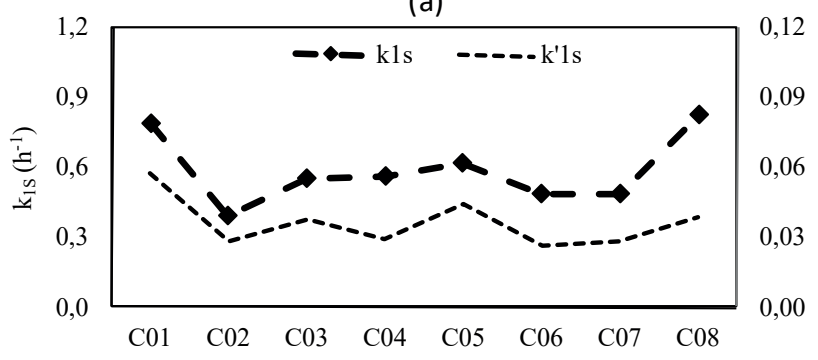

(c)

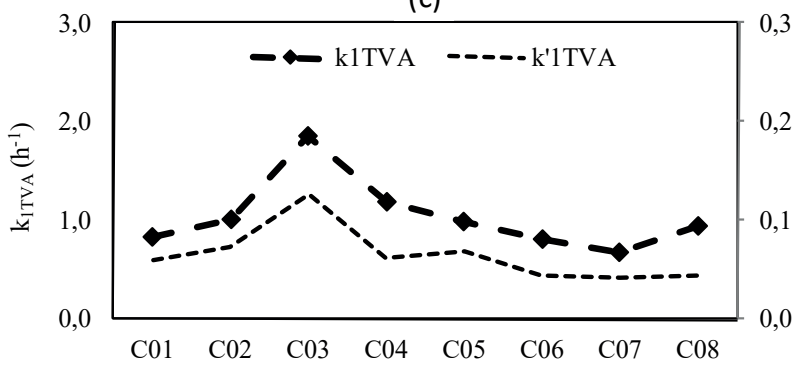

(b)

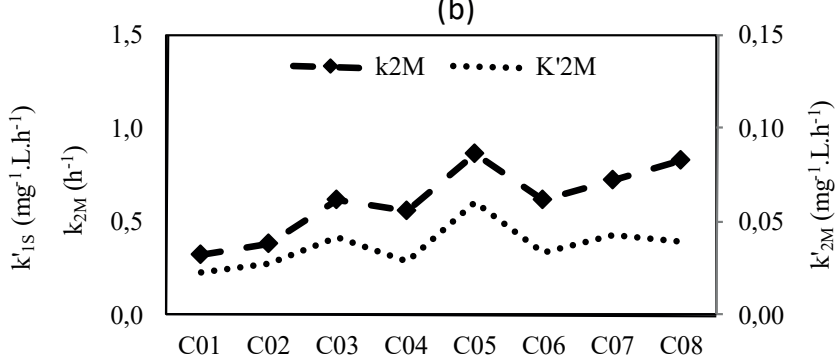

(d)

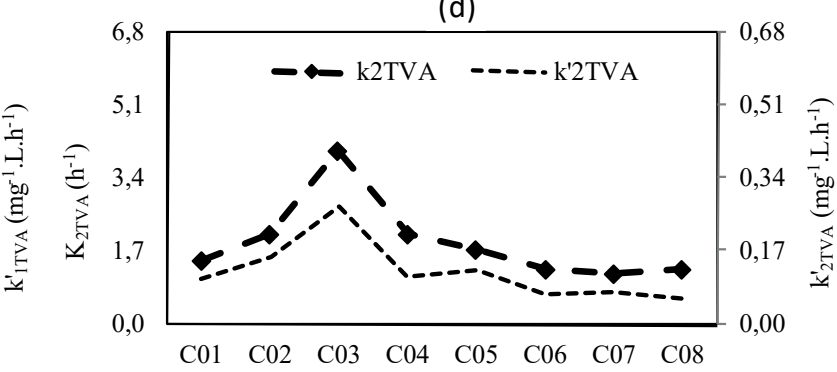

(e)

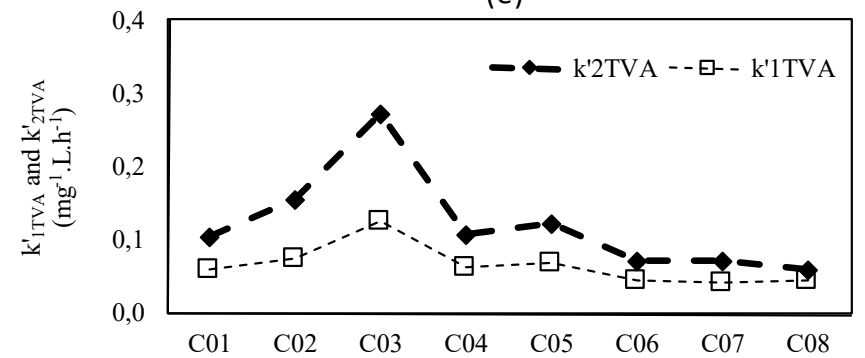

Figure 5. First-order apparent kinetic parameters for the organic matter consumption ( $\left.\mathrm{k}_{1 \mathrm{~S}}\right)$, total volatile acids production $\left(\mathrm{k}_{1 \mathrm{TVA}}\right)$ and consumption $\left(\mathrm{k}_{2 \mathrm{TVA}}\right)$, and methane production $\left(\mathrm{k}_{2 \mathrm{M}}\right)$ and the relation between the specific kinetic parameters for production and consumption of TVA ( $\mathrm{k}_{1 \mathrm{TVA}}$ and $\left.\mathrm{k}_{2 \mathrm{TVA}}\right)$.

Biofilm Reactors (ASBR and AnSBBR), with either liquid phase recirculation (LPR) or mechanical stirring (MS), applied to the treatment of other wastewaters (whey and glycerine). These studies and the present paper assessed experimental conditions with cycle times of $4 \mathrm{~h}$ and $8 \mathrm{~h}$, volume of reactor of 3,0 L or 5,0 L and feed strategy of batch and fed-batch. In the present study the applied volumetric organic load covered a wide range of values, and this made possible the comparison with the other papers.

Mockaitis et al. (2006) treated $2 \mathrm{~L}$ of whey per cycle with an ASBR (MS). The AVOL was in the range of $1.15 \mathrm{gCOD} . \mathrm{L}^{-1} \cdot \mathrm{d}^{-1}$ to $4.79 \mathrm{gCOD} \cdot \mathrm{L}^{-1} \cdot \mathrm{d}^{-1}$. The maximum values of yield, volume and percentage of methane in biogas were, respectively, $5.3 \mathrm{mmolCH}_{4} \cdot \mathrm{gCOD}^{-1}$, $908 \mathrm{NmLCH}_{4}$ and $61 \%$. Selma et al. (2010) treated $2 \mathrm{~L}$ per cycle of an effluent of biodiesel (glycerine) produced in laboratory with an ASBR (MS). The AVOL was in the range of $0.60 \mathrm{gCOD} \cdot \mathrm{L}^{-1} \cdot \mathrm{d}^{-1}$ to $3.82 \mathrm{gCOD} \cdot \mathrm{L}^{-1} \cdot \mathrm{d}^{-1}$. The maximum values of yield, concentration, volume and percentage of methane in biogas were, respectively, $11.8 \mathrm{mmolCH}_{4}$. $\mathrm{gCOD}^{-1}, 11.8 \mathrm{mmol}^{-1}{ }_{\text {biogas }}, 232 \mathrm{NmLCH}_{4}$ and $74 \%$. Lovato et al. (2012) treated 1.5 L per cycle of an effluent of biodiesel (glycerine) produced in laboratory with an AnSBR (LPR). The AVOL was in the range of $4.5 \mathrm{gCOD} . \mathrm{L}^{-}$ ${ }^{1} \cdot \mathrm{d}^{-1}$ to $7.5 \mathrm{gCOD} \cdot \mathrm{L}^{-1} \cdot \mathrm{d}^{-1}$. The maximum values of yield, concentration, and percentage of methane in biogas were, respectively, $5.3 \mathrm{mmolCH}_{4} \cdot \mathrm{gCOD}^{-1}, 13.5 \mathrm{mmol}^{-\mathrm{L}^{-1}}$ biogas and $75 \%$. Finally, Silva et al. (2013) treated $1 \mathrm{~L}$ and $2 \mathrm{~L}$ per cycle of an effluent of biodiesel (glycerine) produced in industry with an ASBR (MS). The AVOL was in the range of $1.23 \mathrm{gCOD} \cdot \mathrm{L}^{-1} \cdot \mathrm{d}^{-1}$ to $3.89 \mathrm{gCOD} \cdot \mathrm{L}^{-1} \cdot \mathrm{d}^{-1}$. The maximum values of yield, concentration, volume and percentage of methane in biogas were, respectively, $11.9 \mathrm{mmolCH}_{4}$. $\mathrm{gCOD}^{-1}, 13.9 \mathrm{mmol}^{-1} \mathrm{~b}_{\text {biogas }}, 319 \mathrm{NmLCH}_{4}$ and $74 \%$.

In general, it can be noted that the ASBR reactor with mechanical stirring treating vinasse presented a better performance than the other reactors treating effluent of biodiesel production (industrial and laboratorial) and whey. In the other studies the yield of methane reached approximately $12 \mathrm{mmolCH}_{4} \cdot \mathrm{gCOD}^{-1}$, but this value is related to a small AVOL. In the present study the maximum yield of methane $\left(13.5 \mathrm{mmolCH}_{4} \cdot \mathrm{gCOD}^{-1}\right)$ is related to an AVOL of 6 to 13 times greater. Besides, the increase in AVOL produced an increase in the yield of methane up 
to the maximum, while in the other reactors a decrease is generally observed.

In addition to the comparison, it can be noted in the literature that there are some studies assessing vinasse treatment using other reactors, such as UASB and USBF (UASB + anaerobic filter). Molina et al. (2007) treated wine vinasse using a hybrid anaerobic reactor (USBF) on a pilot scale with AVOL of $12 \mathrm{gCOD} \cdot \mathrm{L}^{-1} \cdot \mathrm{d}^{-1}$ (in comparison to $10 \mathrm{gCOD} \cdot \mathrm{L}^{-1} \cdot \mathrm{d}^{-1}$ of the present study) and they obtained a COD removal of $96 \%$ and a percentage of methane in biogas of $74 \%$, values that are smaller than that of the present study (98\% e $78 \%$, respectively). On the other hand, España-Gamboa et al. (2012) treated vinasse from hydrous ethanol using a modified UASB reactor with an AVOL of $17 \mathrm{gCOD} \cdot \mathrm{L}^{-1} \cdot \mathrm{d}^{-1}$ and obtained COD removal of $69 \%$, a value that is smaller than that of the present study. These researchers, in turn, obtained a better percentage of methane in biogas, which was $84 \%$.

\section{CONCLUSIONS}

With an increase in the applied volumetric organic load (AVOL) from 1.1 to $10.1 \mathrm{gCOD} \cdot \mathrm{L}^{-1} \cdot \mathrm{d}^{-1}$, the methane productivity increased up to $123.4 \mathrm{molCH}_{4} \cdot \mathrm{m}^{-3} \cdot \mathrm{d}^{-1}$ to reach a maximum yield of $13.5 \mathrm{mmolCH}_{4} \mathrm{gDQO}^{-1}$ in $8.2 \mathrm{gCOD}^{-\mathrm{L}^{-}}$ ${ }^{1} . \mathrm{d}^{-1}$ before decreasing at an AVOL of 10.1 gCOD.L $\mathrm{L}^{-1} \cdot \mathrm{d}^{-1}$. In fed-batch operation, these parameters were smaller (max.: $102.5 \mathrm{molCH}_{4} \cdot \mathrm{m}^{-3} \cdot \mathrm{d}^{-1}$ and $11.80 \mathrm{mmolCH}_{4} \cdot \mathrm{gDQO}^{-}$ ${ }^{1}$ ), and at $45^{\circ} \mathrm{C}$, all of the parameters were reduced (max.: $35.0 \mathrm{molCH}_{4} \cdot \mathrm{m}^{-3} \cdot \mathrm{d}^{-1}$ and $\left.7.10 \mathrm{mmolCH}_{4} \cdot \mathrm{gDQO}^{-1}\right)$. In general, the methane yield and productivity, the kinetic parameters and the overall factors of the degradation process presented here lead to the conclusion that AnSBBR performed well in treating vinasse for applied organic loads up to $10.0 \mathrm{gCOD} . \mathrm{L}^{-1} \cdot \mathrm{d}^{-1}$ and for concentration up to 10.0 gCOD.L ${ }^{-1}$.

Thus, it can be noted that the AnSBBR applied to the treatment of vinasse performed better than other batch reactors applied to the treatment of other wastewaters (whey and glycerine), such as ASBR and AnSBBR that employed liquid phase recirculation. On the other hand, it presented similar performance when compared to continuous reactors, such as UASB, achieving better values for some performance parameters.

The fitting of the proposed model to the data and accumulation of intermediate compounds indicate how the process was dependent of the environmental conditions (AVOL), that could become favourable for some microorganisms and unfavourable for others less adapted. Furthermore, a temperature change should be considered only after sufficient time for biomass adaptation.

Further research in the mesophilic range may focus on the assessment of the effects of changing in the organic load on the process by the variation of the ratio between the feed volume and the reactor volume $\left(\mathrm{V}_{\mathrm{F}} / \mathrm{V}_{\mathrm{R}}\right)$ and by the number of daily cycles $(\mathrm{N})$. Also, it can be suggested that, in the thermophilic range, the effects of changing the organic load on the process be studied by the variation of the influent concentration $\left(\mathrm{C}_{\mathrm{SINF}}\right)$, the ratio $\mathrm{V}_{\mathrm{F}} / \mathrm{V}_{\mathrm{R}}$ and the number of daily cycles $(\mathrm{N})$.

\section{ACKNOWLEDGMENTS}

The authors thank CNPq, CAPES and FAPESP (09/15.984-0 and 13/23366-0) for the financial support.

\section{NOMENCLATURE}

Abbreviation/symbol
AnSBBR
ASBR
COD
$\mathrm{V}_{\mathrm{R}}$
$\mathrm{V}_{\mathrm{F}}$
$\mathrm{N}$
$\mathrm{t}_{\mathrm{C}}$
$\mathrm{t}_{\mathrm{F}}$
$\mathrm{C}_{\mathrm{SINF}}$
$\mathrm{C}_{\mathrm{Sf}}$
$\mathrm{C}_{\mathrm{S} 0}$
$\mathrm{C}_{\mathrm{ST}}$
$\mathrm{C}_{\mathrm{SF}}$
$\varepsilon_{\mathrm{ST}}$
$\varepsilon_{\mathrm{SF}}$
$\mathrm{AVOL}$
$\mathrm{ASOL}$

\section{Denomination}

Anaerobic Sequencing Batch Biofilm Reactor

Anaerobic Sequencing Batch Reactor

Chemical oxygen demand

Volume of liquid into the reactor

Volume of wastewater fed per cycle

Number of cycles per day

Time cycle

Feeding time

Organic matter concentration in influent

Organic matter concentration in feed

Filtered organic matter concentration at initial time of the cycle

Non-filtered organic matter concentration

Filtered organic matter concentration

Efficiency of removal of non-filtered organic matter

Efficiency of removal of filtered organic matter

Applied volumetric organic load, expressed by COD

Applied specific organic load, expressed by COD

\author{
Unit \\ $-$ \\ (mgCOD.L-1) \\ (L) \\ (L.cycle ${ }^{-1}$ ) \\ (cycle. $\mathrm{d}^{-1}$ ) \\ (h) \\ (min) \\ (mgCOD.L $\left.{ }^{-1}\right)$ \\ $\left(\mathrm{mgCOD} . \mathrm{L}^{-1}\right)$ \\ $\left(\mathrm{mgCOD} . \mathrm{L}^{-1}\right)$ \\ $\left(\mathrm{mgCOD} . \mathrm{L}^{-1}\right)$ \\ $\left(\mathrm{mgCOD} . \mathrm{L}^{-1}\right)$ \\ $(\%)$ \\ $(\%)$ \\ $\left(\mathrm{gCOD} \cdot \mathrm{L}^{-1} \cdot \mathrm{d}^{-1}\right)$ \\ $\left(\mathrm{gCOD} \cdot \mathrm{gTVS}^{-1} \cdot \mathrm{d}^{-1}\right)$
}




\begin{tabular}{|c|c|c|}
\hline RVOL & Removed volumetric organic load, expressed by COD & $\left(\mathrm{gCOD} \cdot \mathrm{L}^{-1} \cdot \mathrm{d}^{-1}\right)$ \\
\hline RSOL & Removed specific organic load, expressed by COD & $\left(\right.$ gCOD.gTVS $\left.{ }^{-1} \cdot d^{-1}\right)$ \\
\hline BA & Bicarbonate alkalinity & $\left(\mathrm{mgCaCO}_{3} \cdot \mathrm{L}^{-1}\right)$ \\
\hline TVA & Total volatile acids & $\left(\mathrm{mgHAc} \cdot \mathrm{L}^{-1}\right)$ \\
\hline Acetone & Acetone concentration & $\left(\mathrm{mg} \cdot \mathrm{L}^{-1}\right)$ \\
\hline MetOH & Methanol concentration & $\left(\mathrm{mg} \cdot \mathrm{L}^{-1}\right)$ \\
\hline EtOH & Ethanol concentration & $\left(\mathrm{mg} . \mathrm{L}^{-1}\right)$ \\
\hline ButOH & N-butanol concentration & $\left(\mathrm{mg} . \mathrm{L}^{-1}\right)$ \\
\hline HAc & Acetic acid concentration & $\left(\mathrm{mg} \cdot \mathrm{L}^{-1}\right)$ \\
\hline $\mathrm{HPr}$ & Propionic acid concentration & $\left(\mathrm{mg} \cdot \mathrm{L}^{-1}\right)$ \\
\hline HIsoBut & Isobutyric acid concentration & $\left(\mathrm{mg} \cdot \mathrm{L}^{-1}\right)$ \\
\hline HBut & Butyric acid concentration & $\left(\mathrm{mg} \cdot \mathrm{L}^{-1}\right)$ \\
\hline HIsoVal & Isovaleric acid concentration & $\left(\mathrm{mg} \cdot \mathrm{L}^{-1}\right)$ \\
\hline HVal & Valeric acid concentration & $\left(\mathrm{mg} \cdot \mathrm{L}^{-1}\right)$ \\
\hline $\mathrm{HCa}$ & Caproic acid concentration & $\left(\mathrm{mg} \cdot \mathrm{L}^{-1}\right)$ \\
\hline TS & Total solids & $\left(\mathrm{mgTS} . \mathrm{L}^{-1}\right)$ \\
\hline TVS & Total volatile solids & $\left(\operatorname{mgTVS} . L^{-1}\right)$ \\
\hline TSS & Total suspended solids & $\left(\operatorname{mgTSS} . L^{-1}\right)$ \\
\hline VSS & Volatile suspended solids & $\left(\mathrm{mgVSS} . \mathrm{L}^{-1}\right)$ \\
\hline FSS & Fixed suspended solids & $\left(\mathrm{mgFSS} . \mathrm{L}^{-1}\right)$ \\
\hline TDS & Total dissolved solids & $\left(\operatorname{mgTDS} . \mathrm{L}^{-1}\right)$ \\
\hline VDS & Volatile dissolved solids & $\left(\operatorname{mgVDS} . L^{-1}\right)$ \\
\hline $\mathrm{M}_{\mathrm{TVS}}$ & Mass of total volatile solids in the reactor & $(\mathrm{g})$ \\
\hline $\mathrm{C}_{\mathrm{x}}$ & Mass of total volatile solids per volume of liquid medium & $\left(\mathrm{g} . \mathrm{L}^{-1}\right)$ \\
\hline $\mathrm{C}_{\mathrm{X}}^{\prime}$ & Mass of total volatile solids per mass of inert support & $\left(\mathrm{g} \cdot \mathrm{g}^{-1}\right)$ \\
\hline $\mathrm{V}_{\mathrm{G}}$ & Volume of biogas at STP & $\left(\mathrm{mL}-\mathrm{STP} . \mathrm{cycle}^{-1}\right)$ \\
\hline $\mathrm{V}_{\mathrm{CH} 4}$ & Volume of methane at STP & $\left(\mathrm{mL}-\mathrm{STP}-\mathrm{CH}_{4} \cdot\right.$ cycle $\left.^{-1}\right)$ \\
\hline $\mathrm{N}_{\mathrm{CH} 4}$ & Moles of methane produced & $\left(\mathrm{molCH}_{4} \cdot \mathrm{cycle}^{-1}\right)$ \\
\hline $\mathrm{X}_{\mathrm{CH} 4}^{\mathrm{CH} 4}$ & Percentage of methane in biogas & $(\%)$ \\
\hline $\mathrm{X}_{\mathrm{CO} 2}$ & Percentage of carbonic gas in biogas & $(\%)$ \\
\hline $\mathrm{Y}_{\mathrm{M}-\mathrm{CH} 4 / \mathrm{DQO}}$ & Molar yield of methane from consumed organic matter & $\left(\mathrm{mmolCH}_{4} \mathrm{gCOD}^{-1}\right)$ \\
\hline $\mathrm{Y}_{\mathrm{V}-\mathrm{CH} / \mathrm{COD}}$ & Volumetric yield of methane from consumed organic matter & $\left(\mathrm{mL}-\mathrm{STP}-\mathrm{CH}_{4} \mathrm{gCOD}^{-1}\right)$ \\
\hline MPr & Mol of methane per day and per reactor volume & $\left(\mathrm{molCH}_{4} \cdot \mathrm{m}^{-3} \cdot \mathrm{d}^{-1}\right)$ \\
\hline SMPr & Mol of methane per day and per reactor TVS & $\left(\mathrm{molCH}_{4}^{4} \cdot \mathrm{kgTVS}^{-1} \cdot \mathrm{d}^{-1}\right)$ \\
\hline $\mathrm{VPr}$ & Volume of methane per day and per reactor volume & $\left(\mathrm{mL}-\mathrm{STP}-\mathrm{CH}_{4} \cdot \mathrm{L}^{-1} \cdot \mathrm{d}^{-1}\right)$ \\
\hline SVPr & Volume of methane per day and per reactor TVS & $\left(\mathrm{mL}-\mathrm{STP}-\mathrm{CH}_{4} \cdot \mathrm{gTVS}^{-1} \cdot \mathrm{d}^{-1}\right)$ \\
\hline
\end{tabular}

\section{REFERENCES}

Arooj, M., Han, S., Kim, S., Kim, D., Shin, H., Effect of HRT on ASBR converting starch into biological hydrogen. International Journal of Hydrogen Energy, 33, 6509-6514 (2008).

Bagley, D.M., Brodkorb, T.S., Modelling microbial kinetics in an anaerobic sequencing batch reactor - Model development and experimental validation. Water Environment Research, 71, 1320-1332 (1999).

Bezerra, R.A., Rodrigues, J.A.D., Ratusznei, S.M., Canto, C.S.A., Zaiat, M., Effect of organic load on the performance and methane production of an AnSBBR treating effluent from biodiesel production. Applied Biochemistry and Biotechnology, 165, 347-368 (2011).

Cassidy, D.P., Hirl, P.J., Belia, E., Methane production from ethanol co-products in anaerobic SBRs. Water Science and Technology, 58, 789-793 (2008).
Cassidy, D.P., Hirl, P.J., Belia, E., Methane production from the soluble fraction of distillers' dried grains with solubles in anaerobic sequencing batch reactors. Water Environment Research, 80, 570-575 (2008).

Cesaro, A., Belgiorno, V., Combined biogas and bioethanol production: opportunities and challenges for industrial application. Energies, 2015, 8, 8121-8144 (2015).

Garcia, J.L.; Patel, B.K.C.; Ollivier, B., Taxonomic, phylogenetic and ecological diversity of methanogenic archaea. Anaerobe, 6, 205-226 (2000).

Kim, S., Han, S., Shin, H., Performance comparison of a continuous-flow stirred-tank reactor and an anaerobic sequencing batch reactor for fermentative hydrogen production depending on substrate concentration. Water Science and Technology, 52, 23-29 (2005).

Lovato, G., Bezerra, R.A., Rodrigues, J.A,D., Ratusznei, S.M., Zaiat, M., Effect of feed strategy on methane production and performance of an AnSBBR treating effluent from biodiesel 
production. Applied Biochemistry and Biotechnology, 166, 2007-2029 (2012).

Lullio, T.G., Souza, L.P., Ratusznei, S.M., Rodrigues, J.A.D., Zaiat, M., Biomethane production in an AnSBBR treating wastewater from biohydrogen process. Applied Biochemistry and Biotechnology, 174, 1873-1896 (2014).

Massé, D.I., Croteau, F., Masse, L., Danesh, S., The effect of scaleup on the digestion of swine manure slurry in psychrophilic anaerobic sequencing batch reactors. Transactions of the ASAE, 47, 1367-1374 (2004).

Michelan, R., Zimmer, T.R., Rodrigues, J.A.D., Ratusznei, S.M., de Moraes, D., Zaiat, M., Foresti, E., Effect of impeller type and mechanical agitation on the mass transfer and power consumption aspects of ASBR operation treating synthetic wastewater. Journal of Environmental Management, 90, 1357-1364 (2009).

Mockaitis, G., Ratusznei, S. M., Rodrigues, J. A., Zaiat, M., Foresti, E., Anaerobic whey treatment by a stirred sequencing batch reactor (ASBR): effects of organic loading and supplemented alkalinity. Journal of environmental management, 79 (2), 198-206 (2006).

Ndegwa, P.M., Hamilton, D.W., Lalman, J.A., Cumba, H.J., Optimization of anaerobic sequencing batch reactors treating dilute swine slurries. Transactions of the ASAE, 48, 15751583 (2005).

Pant, D., Adholeya, A., Biological approaches for treatment of distillery wastewater: A review. Bioresource Technology, 98, 2321-2334 (2007).

Rodrigues, J.A.D., Pinto, A.G., Ratusznei, S.M., Zaiat, M., Gedraite, R., Enhancement of the performance of an anaerobic sequencing batch reactor treating low strength wastewater through implementation of a variable stirring rate program. Brazilian Journal of Chemical Engineering, 21, 423-434 (2004).
Ruíz, C., Torrijos, M., Sousbie, P., Lebrato Martínez, J., Moletta, R., Delgenès, J., Treatment of winery wastewater by an anaerobic sequencing batch reactor. Water Science and Technology, 45, 219-224 (2002).

Santos, J.D., Silva, A.L., Costa, J.L., Scheidt, G.N., Novak, A.C., Sydney, E.B., Soccol, C.R., Development of a vinasse nutritive solution for hydroponics. Journal of Environmental Management, 114, 8-12 (2013).

Selma, V.C., Cotrim, L.H.B., Rodrigues, J.A.D., Ratusznei, S.M., Zaiat, M., Foresti, E., ASBR applied to the treatment of biodiesel production effluent: effect of organic load and fill time on performance and methane production. Applied Biochemistry and Biotechnology, 162, 2365-2380 (2010).

Silva, R.C., Rodrigues, J.A.D., Ratusznei, S.M., Zaiat, M., Anaerobic treatment of industrial biodiesel wastewater by an ASBR for methane production. Applied Biochemistry and Biotechnology, 170, 105-118 (2013).

Vlissidis, A., Zouboulis, A., Thermophilic anaerobic digestion of alcohol distillery wastewaters. Bioresource Technology, 43, 131-140 (1993).

Wilkie, A.C., Riedesel, K.J., Owens, J.M., Stillage characterization and anaerobic treatment of ethanol stillage from conventional and cellulosic feedstocks. Biomass and Bioenergy, 19, 63102 (2000).

Zaiat, M., Cabral, A.K.A., Foresti, E., Horizontal-flow anaerobic immobilized sludge reactor for wastewater treatment: conception and performance evaluation. Brazilian Journal of Chemical Engineering, 11, 33-42 (1994).

Zaiat, M., Rodrigues, J.A.D. Ratusznei, S.M., Camargo, E.F., Borzani, W., Anaerobic sequencing batch reactors for wastewater treatment: a developing technology. Applied Microbiology and Biotechnology, 55, 29-35 (2001). 
